İş ve İnsan Dergisi | The Journal of Human and Work

Y1l | Year: Nisan | April 2020

Cilt-Sayı | Volume-Issue: 7 (1)

ss I pp: $147-169$

doi: 10.18394/iid.688722

e-ISSN 2148-967X

http://dergipark.gov.tr/iid/

Derleme Makalesi

\title{
Kültürel Zekâ: Tanımsal, Yapısal ve İlişkisel Bir İnceleme Çalışması *
}

\author{
Cultural Intelligence: A Definational, Structural and Relational Review Study
}

\author{
Selen Doğan ${ }^{a}$, Şenay Karakuş Uysal ${ }^{b}$
}

\begin{tabular}{l} 
MAKALE BİLGİSI \\
\hline Anahtar Kelimeler: \\
Kültür, Kültürel Zekâ, \\
Kültürel Zekâa Ölçeği \\
\hline Tarihler : \\
Geliş 13 Şubat 2020 \\
Düzeltme geliş 20 Şubat \\
2020 \\
Kabul 21 Şubat 2020
\end{tabular}

\section{A R T I C LE INFO}

\section{Keywords:}

Culture, Cultural

Intelligence, The Scale of

Cultural Intelligence

Article history:

Received 13 February 2020

Received in revised form 20

February 2020

Accepted 21 February 2020
ÖZ

Küreselleşme olgusu ile yaygınlaşan, çok kültürlülük, kültürlerarası iletişim, kültürel uyum, kültürel çatışma gibi konular, kültürel zekânın önemini günden güne artırmaktadır. Bu bağlamda, yerli ve yabancı literatürde, kültürel zekâ kavramı ile ilgili yapılan çalışmalar hızla artmaktadır. Bu çalı̧̧mada, kültürel zekâ kavramının yerli ve yabancı literatürde tanımsal, yapısal ve ilişsisel incelemesi yapılarak ilgili alan yazına katkı sağlamak amaçlanmıştır. Çalıșmada, yerli ve yabancı literatüre ait olmak üzere, 2003-2020 yılları arasında yayınlanan 152 araşstırma incelenmiştir. Araştırmaların, 124'ü yabancl, 28'i yerli literatüre aittir. Çalışmada, yer alan araştırmalar, ilk olarak kültürel zekânın ölçülmesi ve öncülleri olarak değerlendirildikten sonra, kültürel zekânın diğer kavramlarla ilişkisi, doğrudan etki, doğrudan olmayan etki, aracl etki, düzenleyici etki ve nitel araştırmalar olmak üzere beş grupta incelenmiştir. Çalı̧̧madan elde edilen sonuçlar, kültürel zekâ ile ilgili yapılan araşstırmaların yıllara göre arttı̆̆ını göstermiștir. İlișkisel incelemeler, kültürel zekânın daha çok doğrudan etki ve doğrudan olmayan etki yöntemi ile incelendiğini ortaya koymuştur. Diğer yandan, yerli literatürde kültürel zekâ ile ilgili oldukça kısıtlı araştırmaların yer aldığı tespit edilmiştir.

\footnotetext{
* Bu çalışma, ikinci yazarın birinci yazar danışmanlığında hazırladı̆̆ ve Kasım 2017’de tamamladığ “ "KOBİ Yöneticilerinin Kültürel Zekâlarının İşletmenin Uluslararasılaşma Derecesine Etkisinde Uluslararasılaşma Tutumunun Aracılık Rolü” isimli doktora tezinden türetilmiştir.

a Prof. Dr., Niğde Ömer Halisdemir Üniversitesi, İktisadi İdari Bilimler Fakültesi, İsletme Bölümü, Niğde, Turkey. E-mail: sdogan01@ohu.edu.tr.ORCID:0000-0002-4019-5581

b Illetişim kurulacak yazar, Dr. Öğr. Üyesi, Aksaray Üniversitesi, Spor Bilimleri Fakültesi, Spor Yöneticiliği Bölümü, Aksaray, Turkey. E-mail: senaykarakusuysal@aksaray.edu.tr. ORCID: 0000-0002-8040-582X
} 


\section{GİRIS}

Küresel ticaret kavramı, yenidünyada, kaynakların kullanımını ve dağılımını evrensel bir hale getirmektedir. Günümüzde gerek özel, gerekse kamu kuruluşları, gelişen teknolojiler, yaygınlaşan uluslararası iletişim kaynakları, taşımacılık sektöründeki ilerlemeler, politik destek ve teşvikler gibi birçok unsur doğrultusunda küresel pazarlarda yerini almaktadır. Diğer yandan, çok kültürlü ortamlarda kültürel farklılıklardan ötürü ortaya çıkan çatışma ve kargaşa ortamı, küresel ticaretin önündeki en önemli engeller arasında yerini almaktadır. Kültürel zekâ, bu çatışma ve kargaşa ortamında kültürel farklılıkların başarılı bir şekilde yönetilmesi adina bir alternatif olarak görülebilmektedir (Yeşil, 2009).

Kültürel zekâ, çok uluslu veya farklı kültürel ortamlarda, bireyin işlevini etkin bir şekilde yerine getirmesini sağlayan yetenekler seti olarak bilinmektedir (Early \& Ang, 2003). Aynı zamanda, kültürel zekâ, farklı kültürlere, etnik kökenlere ve demografik alt yapılara sahip insanların, bir arada en verimli şekilde çalışabilmelerini önermektedir (Johnson, Lenartowich \& Apud., 2006). Kültürel zekâ kavramı ilgili alan yazında çok geçmiş bir tarihe sahip olmamakla birlikte ilk olarak 2000'li yılların bașında yerini almaktadır (Early \& Ang, 2003). Öncelikle işletme ve yönetim alanında yapılan araştırmalarla (Early \& Ang, 2003) gündeme gelen kültürel zekâ kavramı, günümüzde sosyoloji, psikoloji, eğitim vb. birçok farklı alana da konu olmaktadır. Yabancı literatürde kültürel zekâ kavramı ile ilgili yapılmış araştırmaların sayısı oldukça fazladır. Yerli literatürde ise kültürel zekâ ile ilgili yapılan araştırmalar gün geçtikçe artmaktadır.

Bu çalışmanın amacı, kültürel zekânın ilgili alan yazında ilk çıktığı tarihten itibaren, günümüze kadar (2003-2020) yerli ve yabancı literatürde yer alan araştırmaları inceleyerek, kültürel zekânın tanıtılmasını sağlamak ve gelecek araştırmalara kavramla ilgili yol göstermektir. Bu doğrultuda ilk olarak daha önceden kültürel zekâ ile ilgili yapılmış inceleme çalışmaları gözden geçirilmiştir (Andresen \& Bergdolt, 2016; Fang, Schei \& Selart, 2018; Ang, Rockstuhl, \& Tan, 2015; Bücker, 2014; Leung, Ang, \& Tan, 2014; Ng, Van Dyne \& Ang., 2009; Ott \& Michailova, 2018). Ancak yerli literatürde, bu doğrultuda yapılan bir inceleme çalışmasının bulunmaması ve yabancı literatürde yer alan incelemelerin ise 2017 yılına kadar yapılan çalışmalar ile kısıtlı kalması, bu çalışmanın ayırt edici özellikte olduğunu göstermektedir.
Çalışmada yapılan incelemeler, kültürel zekâ kavramının yazında yaygınlığı sebebiyle zaman kısıtı göz önünde bulundurularak "işletme ve yönetim" alanı ile kısıtlandırılmıştır. Daha sonra yazında taranma ve yaygınlığı sebebiyle, yabancı çalışmalar "Web of Science" tabanlı, yerli çalışmalar ise "Dergipark" ve "Akademia" uzantılı olmak üzere kısıtlandırılmıştır. Buradan yola çıkarak çalışmada, 124 yabancı, 28 yerli literatürde yer almak üzere toplamda 152 araştırma incelenmiștir. İncelemeler, "kültürel zekânın ölçülmesi”, "kültürel zekâyı belirleyici öncüller" ve "kültürel zekânın diğer kavramlarla ilişsileri" olmak üzere üç temel alanda gerçekleştirilmiştir. Kültürel zekânın diğer kavramlarla ilişkileri ise sosyal bilimlerde nicel ve nitel araştırma yöntemleri göz önünde bulundurularak "doğrudan etki", "doğrudan olmayan etki", "aracı etki", "düzenleyici etki" ve "nitel araştırmalar" olmak üzere beş ayrı grupta incelenmiştir.

\section{KÜLTÜREL ZEKÂ}

\subsection{Kültürel Zekânın Tanımı}

Kültür kavramı bir zekâ çeşidi olarak ilgili alan yazında ilk defa 2000'li yılların başında yer almıştır. P. Christopher Early ve Soon Ang (2003) yayınlamış oldukları kitapta, ilk defa kültürel zekâyı bir kavram olarak değerlendirmişlerdir. Orijinal adı "Cultural Intelligence" (CQ) olan kavram, Dilimizde Kültürel Zekâ (KZ) olarak kullanılmaktadır. Early ve Ang'a (2003) göre KZ, bireyin işlevini, farklı kültürel ortamlarda veya çok kültürlü ortamlarda etkin bir şekilde yerine getirmesini sağlayan yetenekler setidir. Thomas ve Inkson'a (2005) göre ise KZ, kültürlerarası etkileşimin temellerini anlamayı, bu etkileşimler için dikkatli bir yaklaşım geliştirmeyi ve bireyin farklı kültürel ortamlarda etkili olabilmesi için uyum becerileri ve geniş bir davranıș yelpazesine sahip olmasını ifade etmektedir. Early ve Peterson (2004) kültürel zekâyı, kültürel çeşitliliğin olduğu ortamlarda, bireyin etkin bir şekilde hareket edebilmesi için farklı ipuçlarını toplaması, yorumlaması ve davranışlarını bu doğrultuda yönlendirmesi yeteneği olarak tanımlamaktadır. Thomas ve arkadaşları (2008) ise kültürel zekâyı, meta-bilişsel kültür ile bağlantılı olan ve bireyin çevresindeki farklı kültürel boyutları şekillendirme, seçme ve uyum sağlamasına olanak sağlayan bilgi ve becerilerin etkin olduğu bir sistem olarak ifade etmektedir. Early ve Mosakowski'ye (2004) göre $\mathrm{KZ}$, bireyin, farklı kültürden gelen bireylerin belirsiz ve alışılmadık bedensel hareketlerini, kendi kültüründeki arkadaş çevresine ve kendi kültüründe 
yaşayan insanlara aitmiş gibi yorumlamasını sağlayan doğal bir yetenektir.

KZ, Sternberg ve Determan'in (1986) çok boyutlu zekâ modeline dayandırılmaktadır. Sternberg ve Determan (1986) genel zekâyı, soyut kavramları ve terimleri doğru anlama, kavrama ve problem çözebilme yeteneği olarak tanımlamış ve kişisel zekâ düzeyini açıklayabilecek dört seviye belirlemişlerdir. $\mathrm{Bu}$ seviyeler, üstbilişsel (bilme ve kontrol etme yetisi), bilişsel (kişisel bilgi ve bilgiyi yorumlama yetisi), motivasyonel (sahip olunan bütün enerjiyi öğrenmeye yöneltme yetisi) ve davranışsal (bilgiyi davranışsal boyuta taşıma yetisi) olarak ifade edilmektedir. KZ'da çok boyutlu zekâ modelinde olduğu gibi üstbilişsel, bilişsel, motivasyonal ve davranışsal olarak dört boyutta incelenmektedir (Ang \& Van Dyne, 2008).

Üst bilişsel kültürel zekâ, bireyin kültürler aras1 ortamlarda, kendinden olmayan diğer kültürlerin farkında olmasını içermektedir (Ang \& Van Dyne, 2008). Bu zekâ seviyesine sahip olan bireyler, kültürlerarası etkileşimlerde, kendi kültürüne ait olguları sorgulamakta ve kültürel bilgilerini, karşılaştığ1 yeni kültüre ait olgular ile şekillendirmektedir. $\mathrm{Bu}$ bağlamda, üstbilişsel kültürel zekâ, bireylere, kültürler arası ortamlarda sosyal etkileşimlerde bulunurken sezgilerini ve bireysel normlarını yeni kültür yönünde geliştirmelerine yardımcı olacak önemli bir evredir (Flavell, 1979; Nelson, 1996).

Bilişsel kültürel zekâ, bireyin farklı kültürleri hakkında sahip olduğu bilgiyi ifade etmektedir. $\mathrm{Bu}$ zekâ çeşidine sahip bireyler, diğer kültürlerin benzer yönlerini ve farklı yönlerini bilmekte ve kendi kültürünün bu kültürlerden ayrıştığı yönlerini tespit edebilmektedir (Van Dyne, Ang \& Koh, 2007). Bilişsel kültürel zekâya sahip bireyler, farklı kültürlerin ekonomileri, yasal sistemleri, dini inançları, değerleri, normları, dilleri ve davranışları hakkında bilgi sahibidirler. Diğer kültürler hakkında sahip olunan bu bilgiler, işletme yönetimi alanında bilişsel kültürel zekânın önemli bir evre olduğunu göstermektedir.

Motivasyonel kültürel zekâ, kültürler arası ortamlarda bulunan bireylerin sahip olduğu bütün enerjiyi bu kültürü anlamaya ve öğrenmeye yönlendirmesini ifade etmektedir (Ang \& Van Dayne, 2008). Bu zekâ seviyesine sahip bireyler, farklı kültürel ortamlarda bulunmaktan zevk alırlar ve sürekli yeni kültürleri deneyimlemeye karşı oldukça isteklidirler (Van Dyne vd., 2007). Bu yönde geliştirilmiş kültürel zekâ ise bireyin kültürler arası ortamlarda başarılı bir etkileşim gerçekleştirmesine oldukça katkıda bulunmaktadır.
Davranışsal kültürel zekâda ise kültürel zekânın en ileri boyutu olarak görülmektedir ve bu seviyede bireyler, karşılaştıkları kültüre ait olguları sözel veya sözel olmayan davranışlarını yansıtmaktır (Van Dyne vd., 2007). Hall'e (1959) göre bir kültüre karşı sahip olunan zihinsel bilginin ve bu kültürü öğrenmeye karşı olan isteğinin kesinlikle sözlü veya davranışsal boyuta taşınması gereklidir. $\mathrm{Bu}$ yönde kendini geliştiren bireylerin kültürel ortamlarda yüz yüze etkileşimlerde oldukça başarılı olması beklenmektedir.

\subsection{Kültürel Zekânın Ölçülmesi}

Van Dyne, Ang ve Koh (2007) KZ ölçeğinin, işletmenin diğer kavramlarına ait ölçekler gibi sağlam bir alt yapıya sahip olması ve iyi psikometrik değerler taşıması gerektiğini ön görmektedir. Bu doğrultuda ilk olarak araştırmacılar KZ ile ilişki içinde olabileceğini düşündükleri, Kültür (Adler, 2002; Erez \& Early, 1993; Hofstede, 1991; Triandis, 1994), Göçmen Uyumu (BhaskarShrinivas, Harrison, Shaffer ve Luk, 2005; Black, Gregerson, Mendenhall \& Stroh, 1999; Caligiuri, Hyland, Joshi ve Bross, 1998; Mendenhall \& Oddou, 1985; Shaffer, Harrison, Gregersen, Black \& Ferzandi, 2006, Takeuchi, Tesluk, Yun \& Lepak, 2005), Göçmen Performansı (Caliguiri, 2006; Kraimer, Wayne \& Jaworski., 2001; Ones \& Viswesvaran, 1997; Tung, 1988), Göçmen Seçimi ve Eğitimi (Spreitzer, McCall \& Mahoney, 1997), Küresel Liderlik (House, Hanges, Javidan, Dorfman ve Gupta, 2004), Küresel Takımlar (Kirkman, Tesluk \& Rosen, 2001), Ulus Ötesi Eğitim (Black \& Mendenhall, 1990; Bhawuk \& Brislin, 2000; Landis, Gargas ve Givnish, 2004; Lievens, Harris, Van Keer \& Bisqueret, 2003) ve Kültürleraras1 İletişim (Ting-Toomey, 1999; Gudykunst, TingToomey \& Chua, 1988) gibi kavramlar hakkında yapılan araştırmaları incelemişler ve bu incelemeler doğrultusunda üç odak noktası belirlemişlerdir. İlk olarak, bütün bu araştırmaların ana teması kültürlerarası sorunlardır. İkinci olarak, bu kavramlardan hiç biri bireyin kültürlerarası ortamlarda işlevini başarılı bir şekilde yerine getirebilme yeteneği üzerine odaklanmamıştır ve kültürel zekâ bu konuda eşsiz bir kavram olacaktır. Son olarak, KZ bu kavramlarla ilişki içerisinde olacağı gibi kavramların gelişimine de 1 şık tutacaktır.

Bütün bu incelemelerden sonra araştırmacılar (Van Dyne vd., 2007) kültürel zekânın dört boyutuna ait ölçeği oluşturacak maddeleri ortaya koymuşlardır. Maddeler oluşturulurken ilk olarak, zekâ ve kültürlerarası yetkinliklere ait literatür incelenmiştir. Daha sonra, küresel alanda iş yapan 8 üst düzey yönetici ile görüşme yapılarak kültürel zekânın dört boyutu için operasyonal tanımlamalar 
yapılmıştır. $\mathrm{Bu}$ tanımlamalar doğrultusunda, her bir boyuta 13-14 madde gelecek şekilde 53 maddelik bir soru havuzu oluşturulmuştur. Daha sonra, bu soru havuzu, uluslararası alanda iş yapan üç yönetici ve üç akademisyen ile okunabilirlik, anlaşıla bilirlik ve kapsam açısından değerlendirilerek 40 maddeye indirgenmiştir. Bir sonraki işlemde 40 maddeden oluşan KZ ölçeği, Singapur'da bulunan Nanyang Teknoloji Üniversitesi öğrencilerine uygulanmış ve iyi psikometrik özellik taşıdığı tespit edilen 20 madde ayrıştırılarak ölçek oluşturulmuştur (Ang, Van Dyne, Koh, Ng, Templer, Tay ve Chandrasekar, 2007).

20 maddelik bu ölçek, 4 üst bilişsel, 6 bilişsel, 5 motivasyonal ve 5 davranışsal KZ bileşenini içeren maddelerden oluşmaktadır (bkz. Tablo 1). Ölçek, bireysel değerlendirme için hazırlanmıştır ve grup kullanımı için uygun değildir. Ölçek, 15 yaş ve üzeri yetişkinlere uygulanabilir. Ölçekte zaman sınırlaması yoktur. Ölçek, bir formda bireylerin kendi kendine cevaplandırabileceği şekilde uygulanmaktadır. Ölçekte yer alan sorular, her bir madde için 7'li likert tipi puanlama sistemi ile "Kesinlikle Katılmiyorum", "Katılmıyorum", "Az Katılmiyorum", "Kararsızım", "Az Katılıyorum", "Katılıyorum" ve “ Kesinlikle Katılıyorum" seçenekleri ile uygulanmaktadır. Ölçekte ters olarak kodlanan madde bulunmamaktadır. Ölçeğin puan ranj1 20-140 arasındadır. Ölçekte, toplam puanların değeri kültürel zekâ düzeyini göstermektedir ve puanların yüksekliği, kültürel zekânın yüksek olduğunu ifade etmektedir (bkz. Tablo 1).

\subsubsection{Kültürel Zekânın Ölçülmesi ile İlgili Yapılan Araştırmalar}

Kültürel zekâ ölçeği, yukarıda belirtildiği gibi ilk olarak 2007 yılında Ang ve arkadaşları tarafından geliştirildikten sonra, günümüze kadar diğer araştırmacılar tarafından farklı bakış açıları ile geliştirilmiştir. Yerli ve yabancı literatürde, 2020 yılına kadar yer alan kültürel zekâ ölçeği ile ilgili yapılan araştırmalar aşağıda görülmektedir (Bkz. Tablo 2). Araştırmalar incelendiğinde, ölçekle ilgili ilk yapılan araştırmaların, Kültürel Zeka ölçeğinin,

Tablo 1: Kültürel Zekâ Ölçeği

\begin{tabular}{|c|c|}
\hline CQ Factor & Questionnaire Items \\
\hline \multicolumn{2}{|c|}{ Metacognitive CQ } \\
\hline MC1 & $\begin{array}{l}\text { I am conscious of the cultural knowledge I use when interacting with peoplewith } \\
\text { different cultural backgrounds. }\end{array}$ \\
\hline MC2 & $\begin{array}{l}\text { I adjust my cultural knowledge as Interact with people from a culture that is } \\
\text { unfamiliar to me. }\end{array}$ \\
\hline MC3 & I am conscious of the cultural knowledge I apply the cross-cultural interactions. \\
\hline MC4 & $\begin{array}{l}\text { I check the accuracy of my cultural knowledge as I interact with people from } \\
\text { different cultures. }\end{array}$ \\
\hline \multicolumn{2}{|r|}{ com } \\
\hline COG1 & I know the legal and economic systems of other cultures. \\
\hline COG2 & I know the rules (e.g.vocabulary, grammar) of other languages. \\
\hline COG3 & I know the cultural values and religious beliefs of other cultures. \\
\hline COG4 & I know the marriage systems of other cultures. \\
\hline COG5 & I know the arts and crafts of other cultures. \\
\hline COG6 & I know the rules for expressing nonverbal behaviors in other cultures. \\
\hline \multicolumn{2}{|c|}{ Motivational CQCQ } \\
\hline MOT1 & I enjoy interacting with people from different cultures. \\
\hline MOT2 & I am confidentthat I can socialize with locals in a culture that is unfamiliar to me. \\
\hline MOT3 & I am sure I can deal with the stresses of adjusting to a culture that is new to me. \\
\hline MOT4 & I enjoy living in cultures that are unfamiliar to me. \\
\hline MOT5 & $\begin{array}{l}\text { I am confident that I can get adjustomed to the shopping conditions in a different } \\
\text { culture. }\end{array}$ \\
\hline \multicolumn{2}{|r|}{ ( } \\
\hline BEH1 & $\begin{array}{l}\text { I change my verbal behavior (e.g, Accent, tone) when a cross-cultural interaction } \\
\text { requires it. }\end{array}$ \\
\hline BEH2 & I use pause and silence differently to süit different cross-cultural situations. \\
\hline ВEH3 & I vary the rate of my speaking when a cross-cultural situations requires it. \\
\hline BEH4 & I change my nonverbal behavior when a cross cultural situation requires it. \\
\hline BEH5 & I alter my facial expressions when a cross cultural interaction requires it. \\
\hline
\end{tabular}

Kaynak: Ang vd., 2007 
Duygusal Zekâ (DZ), Sosyal Zekâ (SZ) ve Beş Faktör Kişilik Özellikleri gibi farklı kavramlarla ayrışım özelliklerini ortaya koymaya yönelik olduğu gözlenmektedir (Crowne, 2013; Klafehn, Li \& Chiu, 2013; Moon, 2010a, Ward, Fischer, Lam ve Hall., 2009). Yapılan diğer araştırmalarda ise "Short Form Measure Of Cultural Intelligence (SFCQ)" Kültürel Zekânın Kısa Form Ölçümü (Thomas, Liao, Aycan, Cerdin, Pekerti vd., 2015), "Business Cultural Intelligence Quotient (BCIQ)" Ticari Kültürel Zekâ (TKZ) Uyarlaması (Alon, Boulanger, Meyers, \& Taras, 2016), "Bi-Factor Model of CQ" İki Faktörlü Kültürel Zekâ Modeli (Rockstuhl \& Van Dyne, 2018), "Crossorganizational Cultural Intelligence (COCI)" (Zhou, Hu, Wu \& Gu., 2018) Çapraz Örgütsel Kültürel Zekâ gibi ölçekle ilgili yapısal değişikliklerin yapıldığı dikkat çekmektedir (bkz. Tablo 2).

Kültürel Zekâ Ölçeğinin Türkçe uyarlaması ilk olarak Şahin, Gürbüz, Köksal ve Ercan (2013a) tarafından gerçekleştirilmiştir ve KZ ölçeğinin Türkçe uyarlamasında orjinalde olan dört faktörlü modele uyumlu, iyi psikometrik özellikler gösterdiği tespit edilmiştir. Daha sonra İlhan ve Çetin (2014a), Arastaman (2018) KZ ölçeğinin Türkçe uyarlamasının, sırasıyla öğrencilerde ve akademisyenlerde uygulamak için geçerli ve güvenilir olduğunu tespit etmişlerdir.

Moyano, Tabernero, Melero ve Trujillo (2015) KZ ölçeğinin 4 Faktörlü modelini İspanyolca uyarlamasında doğrularken, Al-dossary (2016) ise Arapça uyarlamasında yine 4 Faktörlü modeli doğrulamıştır. Schlägel ve Sarsted (2016) ise Çin, Fransa, Almanya, Türkiye ve Amerika gibi 5 ülkeyi içeren örneklemden oluşan çalışmaları sonucunda, KZ ölçeğinin yalnızca Türkiye ve Amerika örnekleminde ayrışım göstermediğini ancak özellikle Çin örnekleminde, üst bilișsel ve davranışsal boyutta ayırt edici geçerlilik yetersizliği gösterdiğini tespit etmişlerdir (bkz. Tablo 2).

\subsection{Kültürel Zekânın Öncülleri}

Yerli ve yabancı literatürde, KZ'yı belirleyen faktörler incelendiğinde, KZ'nın oluşumunda en çok etkin olan kavramların, Kültürlerarası Deneyim ve Beş Faktör Kişilik Özellikleri olduğu gözlenmektedir (Bkz. Tablo 3). Kültürlerarası deneyim ile ilgili yapılan araştırmalar, yurtdışında bulunan bireylerin KZ'larının yüksek çıktığı konusunda aynı doğrultuda sonuçlar elde etmiştir (Crowne ,2008; Kurpis \& Hunter, 2017; Li, Mobley \& Kelly, 2013; Moon, Choi \& Jung, 2012; Pekerti \& Arli, 2017; Schwarzenthal, Juang, Schachner, van de Vijver ve Handrick, 2017). Beş Faktör Kişilik Özellikleri ile ilgili yapılan araştırmalarda ise özellikle Dışa Dönüklük ve Deneyime Açıklık kişilik özelliklerinin, KZ'nın dört boyutu ile ayrı ayrı, genel anlamda pozitif yönlü ilişkilere sahip olduğu gözlenmektedir (Ang, Van Dyne \& Koh. 2006; Depaula, Azzollini, Cosentino \& Castillo, 2016; Harrison, 2012; Kement, Çavuşoğlu \& Uslu, 2019; Li, Mobley \& Kelly, 2016; Şahin vd. ,2013a). Diğer yandan, Uyumluluk kişilik özelliğinin de KZ'nın farklı boyutları üzerinde etkin olduğu bazı araştırmalarda gözlenmektedir (Ang vd., 2006; Harrison, 2012; Kement vd., 2019; Li vd., 2016).

Yerli literatürde yer alan araştırmalar incelendiğinde ise yabancı araştırmalarla aynı doğrultuda sonuçlar elde edildiği gözlenmektedir. Şahin ve arkadaşları (2013), Dişa Dönüklüğü yüksek bireylerin, Üstbilişsel ve Motivasyonal KZ'sının daha çok geliştiğini, Deneyime Açıklığ yüksek bireylerin ise Motivasyonal KZ'sının daha çok geliştiğini tespit etmişlerdir. Diğer yandan yine Gökten ve Emil (2019) yaptıkları araştırmada, ERASMUS öğrencilerinin deneyime açıklık özelliklerinin kontrol altında tutulduğunda KZ'nın tüm boyutlarının yüksek çıktığı sonucunu elde etmiştir. Kement ve arkadaşları (2019) uyumluluk kişilik özelliğinin bilişsel KZ'yı, Dışa Dönüklük kişilik özelliğinin Motivasyonal ve Davranışsal KZ'yı, Öz Disiplin kişilik özelliğinin ise yalnızca Davranışsal KZ'y1 etkilediğini tespit etmiştir. Abaslı ve Polat (2019) ise yaptıkları araştırmada Kültürlerarası duyarlılığın KZ'nın önemli bir yordayıcısı olduğunu tespit etmiştir (bkz.Tablo 3).

KZ'nın diğer öncülleri incelendiğinde, dil yeteneği, uluslararası oryantasyon (Li vd. 2013), Öz- İzleme (Moon vd. 2012), Kimlik (Nel, Nel, Adams \& De Beer, 2015), Bağlam Bağımlılı̆̆ı (Adair, Buchan, Chen \& Liu, 2016), Kültürel Sinır (Holtbrügge \& Engelhar, 2016) Tek Kültürlülük ve Çok Kültürlülük (Bernardo \& Presbitero, 2017) gibi kavramların da KZ üzerinde etkin olduğu gözlenmektedir (bkz. Tablo 3).

\subsection{Kültürel Zekânın Diğer Kavramlarla İlişkileri}

Bu çalışmada, KZ'nın ilgili alan yazında yer alan diğer kavramlarla ilişkileri, nicel ve nitel araştırma modelleri ve yöntemleri doğrultusunda gruplar halinde incelenmiştir. Nicel araştırma yöntemleri, yabancı ve yerli literatürde yoğun olması sebebiyle farklı gruplar halinde incelenmiştir. Söz konusu inceleme grupları, nicel araştırma modelleri göz önünde bulundurularak "Doğrudan Etki", "Doğrudan Olmayan Etki”, "Arac1 Etki” ve "Düzenleyici Etki" olarak belirlenmiştir. Doğrudan olmayan etki grubunda, KZ, bağımlı değişkeni bir arac1 veya düzenleyici değişken eşliğinde etkileyen, bağımsız değişken olarak değerlendirilmiştir. Aracı etki grubunda ise KZ'nın aracı değişken olarak yer 
Tablo 2: Kültürel Zekânın Ölçümü ile İlgili Araştırmalar

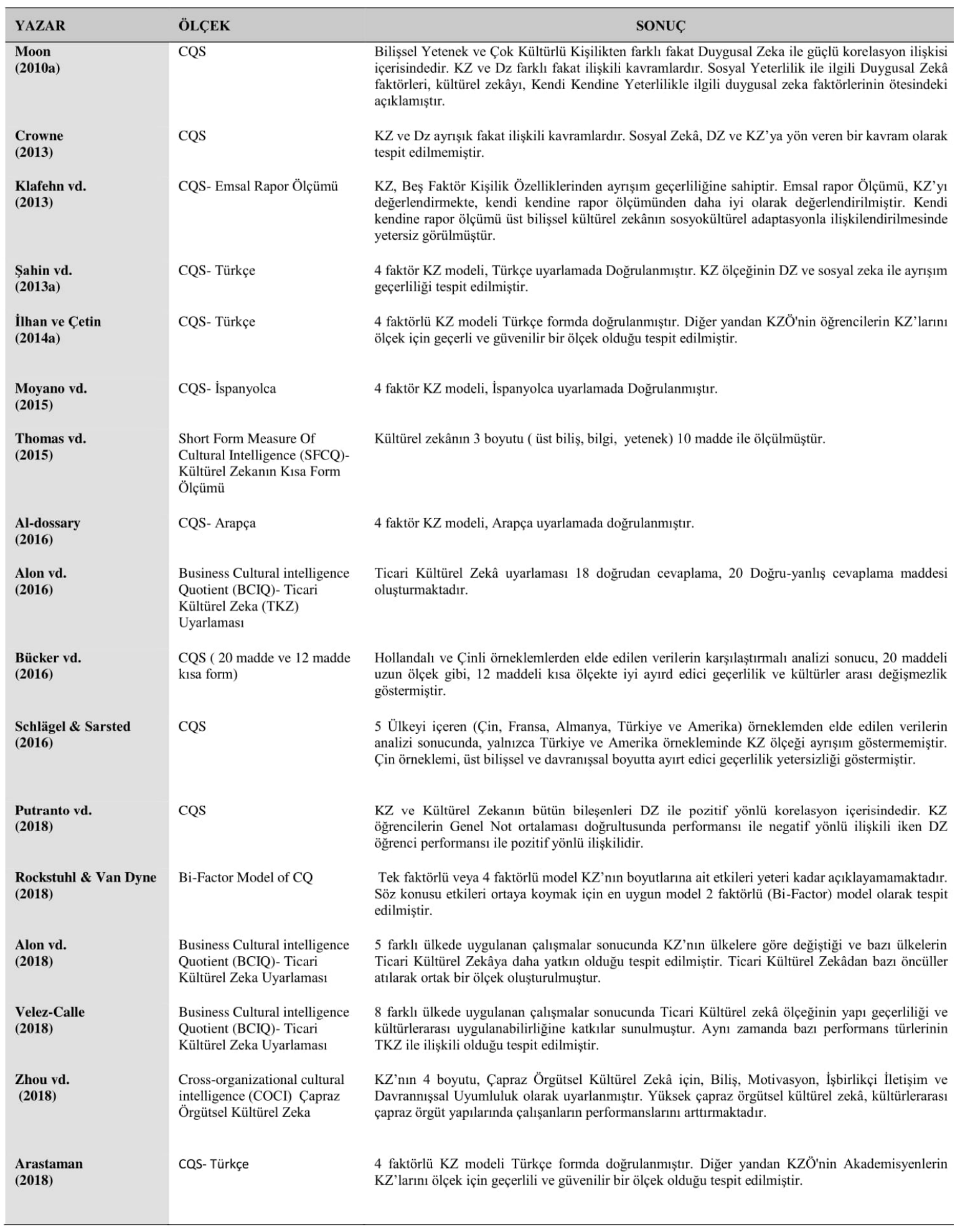

aldığı araştırmalar irdelenmiştir. Nitel araştırma yöntemleri ise tek grup altında incelenmiştir.

\subsubsection{Kültürel Zekâ: Doğrudan Etkisi}

Kültürel zekânın diğer kavramlarla ilgili doğrudan etkisinin olduğu araştırmalar incelendiğinde, yazında en çok Kültürlerarası Etkinlik ile ilintili olduğu tespit edilmiștir (Guðmundsdóttir, 2015; Huff, Song \& Gresch, 2014; Lin, Chen \& Song, 2012; Shu, McAbee \& Ayman, 2017; Zhang \& Oczkowski, 2016). Yapılan araştırmalar KZ'nın, genel anlamda kültürlerarası etkinlik ile pozitif yönlü ilişki içerisinde olduğu sonucunu elde 
Tablo 3: Kültürel Zekânın Öncülleri ile İlgili Yapılan Araştırmalar

\begin{tabular}{|c|c|c|}
\hline YAZAR & ÖNCÜLLER & SONUÇ \\
\hline $\begin{array}{l}\text { Crowne } \\
(2008)\end{array}$ & Kültürlerarası Deneyim & $\begin{array}{l}\text { Yurt dışında bulunmuş kişilerin KZ'sı yüksektir. Yurtdışı istihdam, } \mathrm{KZ} \text { ve Üst bilişssel KZ ile pozitif } \\
\text { yönlü ilişkili iken yurtdıș eğitim, KZ ve dört bileşeni ile pozitif yönde ilişkilidir. Ayrıca Kültürel } \\
\text { Maruz Kalma Derinliği, KZ'yı arttırmaktadır. }\end{array}$ \\
\hline $\begin{array}{l}\text { Li vd. } \\
(2013)\end{array}$ & $\begin{array}{l}\text { Dil Yeteneği } \\
\text { Uluslararası Oryantasyon } \\
\text { Kültürlerarası Deneyim }\end{array}$ & $\begin{array}{l}\text { Dil yeteneği ve Uluslararası oryantasyon, KZ ile pozitif yönlü ilişkilidir. Geçmiş deneyimlerin } \\
\text { uzunluğu, KZ ve dört boyutu ile pozitif yönlü ilişkilidir. Katılımcılar, somut deneyimler ve yansıtıcı } \\
\text { gözlemlerle farklı öğrenme stillerine sahip olduğunda ilişkilerin güçlendiği gözlenmiştir. }\end{array}$ \\
\hline $\begin{array}{l}\text { Şahin vd. } \\
\text { (2013b) }\end{array}$ & Beş Faktör Kişilik Özellikleri & $\begin{array}{l}\text { Dışa dönüklüğü yüksek bireylerin, Üstbilişsel ve Motivasyonal KZ'sı daha çok gelişmiş̧tir. } \\
\text { Deneyime açıklığı yüksek bireylerin ise Motivasyonal KZ'sı daha çok gelişmiştir. }\end{array}$ \\
\hline $\begin{array}{l}\text { Nel vd. } \\
(\mathbf{2 0 1 5})\end{array}$ & $\begin{array}{l}\text { Kimlik } \\
\text { ( Kişisel, Çok-Etnik, Din ) }\end{array}$ & $\begin{array}{l}\text { Akılcı, Kolaylaştırıcı ve Etnik kimlik, Bilişsel KZ'nın pozitif belirleyicisidir. Dini kimlif ise negatif } \\
\text { belirleyicisidir. Yumuşak kalp, Kolaylaştırııı, Dışa Dönük ve Dini kimlik Motivasyonal KZ'nın } \\
\text { pozitif belirleyicisidir. Yumuşak Kalp ve Dürüstlük, davranışsal KZ'nın pozitif belirleyicisidir. }\end{array}$ \\
\hline Adair vd. & $\begin{array}{l}\text { Kişilik } \\
\text { Bağlam Bağımlılığı }\end{array}$ & İletişimde bağlamsal işaretlere daha çok yatkın olan insanlar, yüksek KZ'ya sahiptir. \\
\hline $\begin{array}{l}\text { Depaula vd. } \\
(2016)\end{array}$ & $\begin{array}{l}\text { Beş Faktör Kişilik Özellikleri } \\
\text { Sosyal Zeka }\end{array}$ & $\begin{array}{l}\text { Açıklık, KZ'nın pozitif belirleyicisidir. Sosyal Zekâ ise KZ'nın diğer belirleyicilerden daha fazla } \\
\text { pozitif beliryecisidir. }\end{array}$ \\
\hline $\begin{array}{l}\text { Presbitero } \\
(2017)\end{array}$ & Çok Kültürlülük & $\begin{array}{l}\text { kültür arasında } \mathrm{KZ} \text { dereceleri farklılık göstermektedir. Çok külttürlülük ise yalnızca Çin } \\
\text { örnekleminde KZ'nın belirleyicidir. }\end{array}$ \\
\hline $\begin{array}{l}\text { Kurpis \& Hunter } \\
(2017)\end{array}$ & Kültürlerarası Deneyim & $\begin{array}{l}\text { Kültürlerarası Deneyime bağlı eğitim, Üst Bilişsel KZ hariç KZ'nın diğer boyutları ile pozitif yönlü } \\
\text { ilişkilidir. Kültürlerarası Deneyime dayalı çalş̧ma veya seyahat ise KZ'nın bütün boyutlanı ile pozitif } \\
\text { yönlü ilişkilidir. }\end{array}$ \\
\hline $\begin{array}{l}\text { Pekerti \& Arli } \\
\text { (2017) }\end{array}$ & Kültürlerarası Deneyim & $\begin{array}{l}\text { Avusturalya, Endonezya ve Avusturalya'da yaşayan Endonezyalı göçmenler örnekleminin } \\
\text { karşılaştırmasında, Göçmenler KZ'sı en yüksek olan grup olarak tespit edilmiştir. }\end{array}$ \\
\hline $\begin{array}{l}\text { Schwarzenthal vd. } \\
\text { (2017) }\end{array}$ & Kültürlerarası Deneyim & $\begin{array}{l}\text { Miras Kültür Keşfi ve Kültürlerarası Bağlantı, KZ'nın bütün boyutlarının pozitif belirleyicisidir. Yaş } \\
\text { ise KZ ile korelasyon içinde değildir. }\end{array}$ \\
\hline $\begin{array}{l}\text { Gökten \& Emil } \\
\text { (2019) }\end{array}$ & $\begin{array}{l}\text { ERASMUS Öğrenim Hareketliliği, } \\
\text { Deneyime Açıklık }\end{array}$ & $\begin{array}{l}\text { ERASMUS öğrenim hareketliliği programı, deneyime açıklık kişilik özelliği kontrol altında } \\
\text { tutulduğunda KZ'nın tüm boyutlarını olumlu yönde etkilemektedir. Deneyime açılık araştırmanın } \\
\text { eşdeğişkenidir. }\end{array}$ \\
\hline $\begin{array}{l}\text { Abasli v\& Polat } \\
\text { (2019) }\end{array}$ & Kültürlerarası Duyarlılık & Kültürlerarası duyarlılık KZ’nın anlamlı bir yordayıcısıdır. \\
\hline $\begin{array}{l}\text { Kement vd. } \\
(2019)\end{array}$ & Beş Faktör Kişilik Özellikleri & $\begin{array}{l}\text { Uyumluluk, bilişssel KZ'yı, dışa dönüklük, Motivasyonal ve davranışsal KZ'yı, Öz disiplin ise } \\
\text { yalnızca Davranışsal KZ'yı etkilemektedir. }\end{array}$ \\
\hline
\end{tabular}

etmiştir (Bkz.Tablo 4). Diğer yandan, Rockstuhl, Seiler, Ang, Van Dyne ve Annen (2011) KZ'nın, sınırlar ötesi ortamlarda liderlik etkisi ile pozitif yönlü ilişkili olduğunu ortaya koyarken, Khani, Etebarian ve Abzari (2011) ise takım etkisininde KZ ile pozitif ilişkiler içinde olduğunu tespit etmiştir.

Tablo 4 incelendiğinde, KZ'nın farklı performans çeşitleri ile de sık sık etkileşim içerisinde olduğu görülmektedir. Görev performansı (Presbitero, 2016a; Şahin \& Gürbüz, 2012), iş performansı
(Wang, 2016), lider performans1, takım performans1 (Groves \& Feyerherm, 2011) ve uyum performans1 (Suharti, Handoko \& Huruta 2019), KZ'nın etkileşim içerisinde olduğu performans çeşitleri arasında yerini almaktadır. Yapılan çalışmaların sonuçları irdelendiğinde KZ'nın, görev performans1, iş performansı, takım performansı veya liderlik performansı ile pozitif yönlü ilişkili olduğu görülmektedir. Diğer yandan, KZ, göçmen öğrencilerin uyum performansını pozitif yönde etkilemektedir (Suharti vd., 2019). 
Tablo 4: Kültürel Zekânın Doğrudan Etkileşimi ile İlgili Araştırmalar

\begin{tabular}{|c|c|}
\hline YAZAR & DEĞİŞKEN \\
\hline $\begin{array}{l}\text { Templer, Tay \& } \\
\text { Chandrasekar } \\
\text { (2006) }\end{array}$ & Kültürlerarası Uyum \\
\hline $\begin{array}{l}\text { Joardar vd. } \\
\text { (2007) }\end{array}$ & Grup kabulü \\
\hline $\begin{array}{l}\text { Groves \& Feyerherm } \\
\text { (2011) }\end{array}$ & $\begin{array}{l}\text { Lider Performansı, Takım } \\
\text { Performansı }\end{array}$ \\
\hline $\begin{array}{l}\text { Khani vd. } \\
\text { (2011) }\end{array}$ & Takım Etkisi \\
\hline $\begin{array}{l}\text { Rockstuhl vd. } \\
\text { (2011) }\end{array}$ & Liderlik Etkisi \\
\hline $\begin{array}{l}\text { Ward vd. } \\
(2011)\end{array}$ & Adaptasyon Problemi \\
\hline $\begin{array}{l}\text { Şahin } \\
\text { (2011) }\end{array}$ & $\begin{array}{l}\text { Örgütsel Vatandaşlık Davranışı } \\
\text { (ÖVD), İș Doyumu }\end{array}$ \\
\hline $\begin{array}{l}\text { Lin vd. } \\
(\mathbf{2 0 1 2})\end{array}$ & Kültürlerarası Etkinlik \\
\hline $\begin{array}{l}\text { Şahin \& Gürbüz } \\
\text { (2012) }\end{array}$ & $\begin{array}{l}\text { Örgütsel Vatandaşlık Davranışı, } \\
\text { Görev Performansı }\end{array}$ \\
\hline $\begin{array}{l}\text { Grand vd. } \\
\text { (2013) }\end{array}$ & $\begin{array}{l}\text { Önyargıyı belirleyen faktör olarak } \\
\text { Doğruluk }\end{array}$ \\
\hline $\begin{array}{l}\text { Bücker vd. } \\
\text { (2014) }\end{array}$ & Kaygı, İș Doyumu \\
\hline $\begin{array}{l}\text { Huff vd. } \\
\text { (2014) }\end{array}$ & Kültürlerarası Etkinlik \\
\hline $\begin{array}{l}\text { Kanten } \\
(\mathbf{2 0 1 4})\end{array}$ & $\begin{array}{l}\text { Kariyer Yetkinlikleri, Müşteri Odaklı } \\
\text { Hizmet davranışları. }\end{array}$ \\
\hline $\begin{array}{l}\text { İlhan \& Çetin } \\
\text { (2014b) }\end{array}$ & Sosyal Zeka \\
\hline $\begin{array}{l}\text { Guðmundsdóttir } \\
\text { (2015) }\end{array}$ & Kültürlerarası Etkinlik \\
\hline $\begin{array}{l}\text { Lisak \& Erez } \\
\text { (2015) }\end{array}$ & Liderliğin Doğuşu \\
\hline $\begin{array}{l}\text { Aslam, Ilyas, Imran \& Ur } \\
\text { Rahman, } \\
\text { (2016) }\end{array}$ & Kariyer Başarısı, Yönetsel Etkinlik \\
\hline $\begin{array}{l}\text { Presbitero } \\
\text { (2016a) }\end{array}$ & Görev Performansı \\
\hline $\begin{array}{l}\text { Wang } \\
(2016)\end{array}$ & İş Performansı \\
\hline $\begin{array}{l}\text { Zhang \& Oczkowski } \\
(\text { (2016) }\end{array}$ & Kültürlerarası Etkinlik \\
\hline $\begin{array}{l}\text { Büyükbeşe \& Yıldız } \\
\text { (2016) }\end{array}$ & Yaşam Doyumu \\
\hline $\begin{array}{l}\text { Delpechitre \& Baker } \\
\text { (2017) }\end{array}$ & $\begin{array}{l}\text { Uyarlanabilir Satış Davranışları, Rol } \\
\text { Yapma Performansı }\end{array}$ \\
\hline $\begin{array}{l}\text { Ramsey vd. } \\
(2017)\end{array}$ & Dönüştürücü Liderlik \\
\hline $\begin{array}{l}\text { Shu vd. } \\
\text { (2017) }\end{array}$ & Kültürlerarası Etkinlik \\
\hline $\begin{array}{l}\text { Solomon \& Steyn } \\
\text { (2017) }\end{array}$ & Liderlik \\
\hline
\end{tabular}

Küresel profesyonellerin motivasyonal KZ'sının, is ve yașam koșulları hakkında beklentileri kontrol edildikten sonra kültürlerarası uyumun üç faktörü ( iș, genel, etkileșim) ile pozitif yönde ilișkili olduğu yespit edilmiștir.

Acemi KZ'sı, ilgili yeni gelenlerin grup kabulü ile pozitif yönlü ilișki içerisindedir.

Liderlerin genel KZ'sı, lider peformansı ve kültürel farklılıklar içeren çalıșma gruplarının takım performansında, DZ'dan daha yüksek pozitif yönlü ilișki içerisindedir.

$\mathrm{KZ}$ ve dört boyutu grup etkisi ile pozitif yönlü ilişkilidir. Motivasyonal KZ ve Davranışsal KZ, takım etkisini öngörmektedir.

$\mathrm{KZ}$, genel zihinsel yetenek ve DZ kontrol edildikten sonra, sınır ötesi liderlik etkinliğ ile pozitif yönlü ilișkili bulunmuş ancak genel liderlik etkinliği ile ilișkili bulunmamıștır.

Motivayonal KZ, adaptasyon peroblemleri ile negatif yönlü iliş̧ilidir. Yaş, cinsiyet, yurtdışında ikamet süresi ve menșe bölgesi değişkenlerinin kontrolleri, mode tarafından açıklanan varyans miktarı doğrulltusunda anlamlı değildi.

Motivasyonal ve davranıssal KZ, astların ÖVD ve lider kaynaklı is doyumlanı ile ilișkilidir. Ancak Bișilsel ve Üst bilișsel KZ'nın ÖVD ve İs doyumu ile ilișkiler zayf ve anlamsizdır.

Cinsiyet, yaş, uluslararası tecrübe ve yabancı dil yeteneği değişkenleri kontrol edildikten sonra, $\mathrm{KZ}$ ve dört ayrı boyutu Kültürlerarası Etkinlik ile pozitif yönlü ilișkili bulunmuştur.

Çokuluslu örgütlerde, KZ, gerek ÖVD gerekse görev performansı üzerinde olumlu etkiye sahiptir.

Sözlü yapılan yetenek testi sonucunda KZ'nın hiçbir boyutunun, önyargıyı belirleyen doğruluk ile ilișki içerisinde olmadığı tespit edilmiștir.

Genel KZ, Kaygı ile negatif yönlü, İş doyumu ve Etkili iletişim ile pozitif yönlü ilişkilidir.

KZ, Kültürlerarası Etkinliğin Üç boyutu ile Beș Faktör Kișilik Özelliklerinden daha fazla pozitif yönlü ilișki içerisindedir.

$\mathrm{Kz}$ ile kriyer yetkinlikleri arasında anlamlı bir iliski vardır. Aynı zamanda KZ, is görenlerin müşteri odaklı hizmet davranışları üzerinde etkin rol oynamaktadır.

Sosyal zeka ve kültürel zeka arasında anlamlı bir ilişsi vardır.

Üst bilisssel KZ, kültürlerarası etkinliğin Üç boyutu ile ( iș, genel, etkileșim) pozitif yönlü ilișkilidir. Motivayonal KZ, Genel ve Etkileșim boyutu ile pozitif yönlü ilișilidir.

Sanal ekip üyeleri içerisinde yüksek KZ, Küresel Kimlik ve Farklılıklara Açıklığa sahip bireyler, diğerlerinden daha çok lider olarak doğmuş̧ur.

DZ, Kariyer başarısı ve Yönetsel etkinliğin belirleyici etkeni olmasına rağmen, Kültürel zeka değișkenlerle belirgin etkinlik içerisinde değildir.

KZ’nın dört boyutu, Sanal ekiplerin görev performansı ile pozitif yönlü ilişkilidir.

Genel KZ, Gurbetçilerin İş Performansı ile pozitif yönlü ilişsilidir.

Motivasyonal KZ, Kültürlerarası Etkinlik ile pozitif yönlü ilișkilidir. KZ ve Kültürlerarası Etkinlik arasındaki ilișkide, Kültürel Mesafe Asimetrisinin Moderatör etkisi bulunmamıștır.

Üst bilişsel ve Motivasyonal KZ, yaşam doyumunu anlamlı ve olumlu yönde etkilemektedir.

CQ'ları daha yüksek olan öğrenciler satıș davranıșlarını daha iyi ayarlayabilir ve daha yüksek bir performans sergileyebilirler.

Genel KZ, küresel liderlerin Dönüştürücü Liderliği ile pozitif yönlü ilișkilidir Uluslararası Tecrübe sôz konusu ilișkiyi güçlendirmektedir.

KZ'nın dört boyutu, Kültürlerarası Etkinlik ile pozitif yönlü ilişkilidir. Etkileșim boyutunda, dışadönüklük, $\mathrm{KZ}$ üzerinde öngörülür bir etkiye sahipti. Okul ile uyum boyutunda, Dürüstlük, KZ üzerinde öngörülür bir etkiye sahipti.

Liderin davranışsal KZ'sı direktif liderlik ile pozitif yönlü ilişkili iken, Üstbilişsel ve Motivasyonal KZ'sı güçlendirici liderlik ile pozitif yönlü iliskilidir. Güçlendirici Liderlik ve KZ arasındaki korelasyon iliskisi, Direktif Liderlik ve $\mathrm{KZ}$ arasındaki korelasyon ilişkisinden daha güçlüdür. 
Yerli literatür incelendiğinde, $\mathrm{KZ}$ ile ilgili yapılmış pek çok araştırmanın "doğrudan etki" yöntemi ile incelendiği görülmektedir. Örgütsel Vatandaşlık Davranış1 (Şahin, 2011; Şahin \& Gürbüz, 2012), Kariyer Yetkinlikleri ve Müșteri Odaklı Hizmet Davranışları (Kanten, 2014), Sosyal Zeka (İlhan \& Çetin, 2014b), Yaşam Doyumu (Büyükbeşe \& Yıldız, 2016), Çok Kültürlü Eğitime Yönelik Tutum (Ekici, 2017; Gezer \& Şahin 2017), Kültürel Farklılıkların Yönetimi (Kulakoğlu \& Topaloğlu 2017), Öz-Yeterlilik (Yıldırım \& Köroğlu 2019), Duygusal Emek (Taşdemir, Çekmecelioğlu \& Yıkılmaz 2019) ve Girişimcilik Yönelimi (Koyuncu \& Akdöl, 2019) yerli literatürde KZ ile etkileşim içerisinde incelenmiş kavramlar arasında yerini almaktadır (bkz. Tablo 4).

\subsubsection{Kültürel Zekâ: Doğrudan Olmayan Etkisi}

Kültürel Zekâ, Doğrudan Olmayan Etki, KZ'nın bazı bağımlı değişkenler üzerinde, aracı veya düzenleyici değişkenler vasıtasıyla etkili olduğu veya etkisinin arttığ $1 /$ azaldığ 1 durumları ifade etmektedir. Tablo 5 , bu bağlamda, yabancı ve yerli literatürde inceleme konusu olan ve $\mathrm{KZ}$ ile etkileşim halinde olan bağımlı değişkenleri ve arac1/düzenleyici değişkenleri göstermektedir. Bu doğrultuda Tablo 5 incelendiğinde, KZ'nın en çok bir aracı veya düzenleyici değişken eşliğinde, Kișisel Performans (Chen, Lin \& Sawangpattanakul, 2011; Lee \& Sukoco, 2010), Görev Performans1 (Jyoti \& Kour, 2015, 2017; Malek \& Budwar, 2013; Presbitero \& Toledano, 2018) ve İhracat Performans1 (Charoensukmongkol, 2015) üzerinde etkili olduğu görülmektedir. KZKişisel Performans ilişkisinde, kültürlerarası uyum ve kültür şoku, KZ-Görev Performansı ilişkisinde, farklı farklı araştırmalarda yine kültürlerarası uyum ve temas yoğunluğu, KZ-İhracat Performans1 arasındaki ilişkide ise Bilgi Edinme Yeteneği ve İlişki Kalitesi gibi değişkenlerin etkin olduğu gözlenmektedir (bkz. Tablo 5).

Yerli literatürde ise yapılan incelemeler sonucunda, doğrudan olmayan etki grubunda yalnızca Çalışkan, Ünal, Kalafatoğlu, Üçler ve Akün (2015) araştırması olduğu tespit edilmiştir. Çalışkan ve arkadaşları (2015), KZ, Örgütsel Sinizm, Farklılık İklim Algısı ve Gelişime Açıklık kavramları arasındaki ilişkileri inceledikleri araştırmada, farklılık iklim algısının KZ ve örgütsel sinizm arasındaki ilişkide aracılık rolü üstlendiğini tespit etmişlerdir. Diğer yandan, Gelişime Açıklık, KZ ve Farklılık İklim Algısı arasında şartlı değişken rolü üstlenmemektedir (bkz. Tablo 5).

\subsubsection{Kültürel Zekâ: Aracı Etkisi}

KZ'nın yerli ve yabancı literatürde aracılık rolü üstlendiği araştırmalar Tablo 6'da görülmektedir. Aracılık etkisini ele alan araştırmalar incelendiğinde, KZ'nın genel çerçevede benzer değişkenler arasında aracılık ettiği söylenemez. Gerek yabanc1, gerekse yerli literatürde KZ'nın aracılık etkisi farklı değişkenler doğrultusunda gerçekleştirilmiştir. Elde edilen sonuçlarda ulaşılan genel kanı, yalnızca KZ'nın çoğu araştırmada tamamen aracılık ettiği yönündedir.

KZ, geçmiş kültürlerarası iletişim ve liderlik potansiyeli (Kim \& Van Dyne, 2012), geçmiş uluslararası iş dişı deneyim ve ayrılık öncesi eğitim (Moon vd. ,2012), dil yeteneği ve yurtdışı çalışma niyeti (Remhof, Gunkel \& Schlägel 2013), kültürel psikolojik sermaye ve üst bilişsel farkındalık (Remhof, Gunkel \& Schlägel, 2014), bireysel uyarlanabilir performans ve öz-yeterlilik/geçmiş deneyim, deneyime açıklık ve iş doyumu (Şahin \& Gürbüz, 2014), çok kültürlülük ve yaratıcı iş davranış1 (Korzilius, Bücker \& Beerlage, 2017), dil yeteneği ve görev perfromans1 (Presbitero, 2017), uluslararası seyahat deneyimi/kültürlerarası sosyal iletişim ve göçmenlik isteği (Lee, Webera, Rivera, 2019) arasındaki ilişkide pozitif yönlü, tamamen aracılık rolü üstlenmektedir (Bkz. Tablo 6). Diğer yandan, yurtdışı deneyimi ve yurtdışı çalışma niyeti (Remhof vd., 2013), kültürlerarası deneyim ve yaratıcılık (Hu vd., 2017), kişilik ve yaşam doyumu (Wang, Wang, Heppner \& Chuang, 2017) arasındaki ilişkide ise KZ'nın kısmi aracılık rolü bulunmaktadır (Bkz. Tablo 6).

Yerli literatürde ise KZ'nın aracılık rolü yalnızca Şahin ve Gürbüz (2014) tarafindan incelenmiştir. Şahin ve Gürbüz (2014) yaptıkları araştırmada, özyeterlilik ve geçmiş uluslararası deneyimin KZ'yı etkilediğini, KZ'nın ise bu doğrultuda bireysel uyarlanabilir performansı artırdığını tespit etmişlerdir (bkz. Tablo 6).

\subsubsection{Kültürel Zekâ: Düzenleyici Etkisi}

Yerli ve yabancı literatürde KZ'nın düzenleyici etkisini çalışan araştırmalar incelendiğinde, aracı etkide olduğu gibi genel bir kanının olduğu veya benzer değiş̧kenler üzerinde çalışıldığg söylenemez. Düzenleyici etkiyi ele alan araştırmalar incelendiğinde, KZ'nın çoğu değişken arasındaki ilişkide olumlu yönde düzenleyicilik rolü üstlendiği söylenebilir (bkz. Tablo 7). Ancak bazı araştırmalarda, KZ'nın boyutlarına ait düzenleyicilik rolü farklılık göstermektedir. Örneğin, Wu ve Ang (2011) yaptıkları araştırmada, Üst bilişsel ve Bilişsel KZ'nın, yabancılara ait desteklenen pratiğin alışma üzerine olumlu etkisini azaltırken, Motivasyonal KZ'nın ise artırdığını tespit etmiştir. Magnusson, Westjohn, Semenov, Randrianasolo ve Zdravkovic (2013) ise yaptıkları 
araştırmada, Üst Bilişsel KZ'nın, pazarlama karmas1 uyumunun ihracat performans1 üzerine olumlu etkisini artırdığını, Motivasyonal KZ'nın ise çevresel farklılığın pazarlama karması uyumu üzerine pozitif yönlü etkisini artırdığını tespit etmişlerdir.

Tablo 5: Kültürel Zekâ Doğrudan Olmayan Etki ile İlgili Araştırmalar

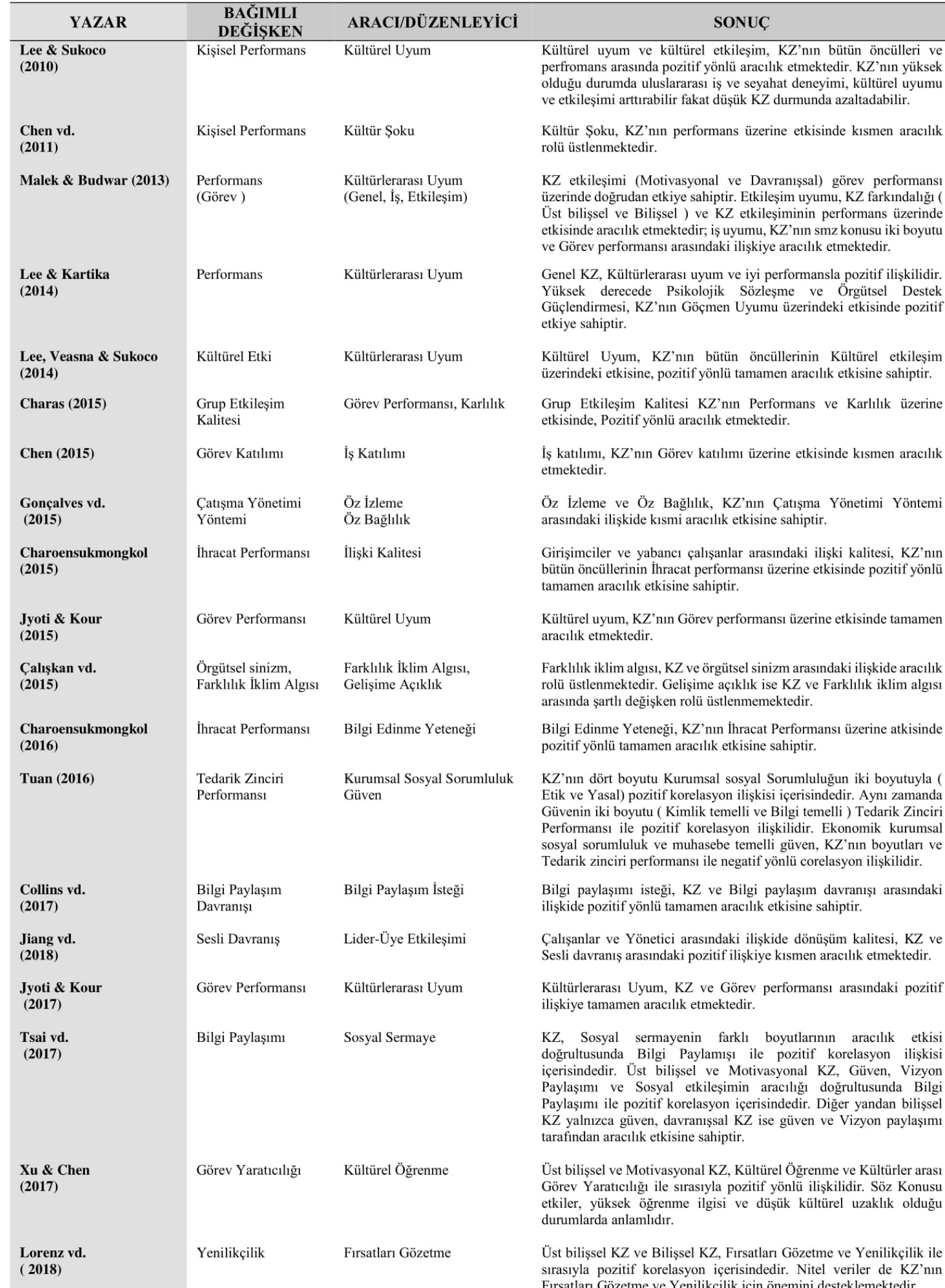


Tablo 5: Kültürel Zekâ Doğrudan Olmayan Etki ile İlgili Araştırmalar (Devamı)

\begin{tabular}{|c|c|c|}
\hline $\begin{array}{l}\text { Jiang vd. } \\
\text { (2018) }\end{array}$ & Sesli Davranış & Lider-Üye Etkileşimi \\
\hline $\begin{array}{l}\text { Presbitero \& } \\
\text { Toledano (2018) }\end{array}$ & $\begin{array}{l}\text { Bireysel Düzeyde } \\
\text { Görev Performansı }\end{array}$ & Temas Yoğunluğu \\
\hline $\begin{array}{l}\text { Berraies } \\
\text { (2019) }\end{array}$ & Yenilik Performansı & Bilgi Paylaşımı, Ortak İklim \\
\hline $\begin{array}{l}\text { Kadam vd. } \\
\text { (2019) }\end{array}$ & Performans & Girişimcilik Yönelimi \\
\hline $\begin{array}{l}\text { Coster vd. } \\
\text { (2019) }\end{array}$ & $\begin{array}{l}\text { Servis İyileștirme } \\
\text { performansı }\end{array}$ & İş Randevusu \\
\hline $\begin{array}{l}\text { Sharma } \\
\text { (2019) }\end{array}$ & Kurumsal Başarı & İliş̧ki Kalitesi \\
\hline $\begin{array}{l}\text { Akhal \& Liu } \\
(2019)\end{array}$ & İșten Ayrılma Niyeti & $\begin{array}{l}\text { Göçmenlerin kültürlerarası } \\
\text { Uyumu }\end{array}$ \\
\hline $\begin{array}{l}\text { Caputo vd. } \\
\text { (2019) }\end{array}$ & Kültürel Değerler & Müzakere Yöntemleri \\
\hline Vlajcic vd. (2019) & Bilgi Paylaşımı & Coğrafik Uzaklık \\
\hline $\begin{array}{l}\text { Hu, Gu, Liu \& Huang. } \\
\text { (2017) }\end{array}$ & $\begin{array}{l}\text { Yaratıcilık } \\
\text { performansı }\end{array}$ & $\begin{array}{l}\text { İlişki Çatış̧maları } \\
\text { Görev Çatışmaları }\end{array}$ \\
\hline
\end{tabular}

KZ'nın sesli davranış üzerine olumlu yönde etkisine lider-üye etkileşimi kısmen aracılık etmektedir.

$\mathrm{KZ}$, kültürlerarası eğitimle artmaktadır. Artan $\mathrm{KZ}$ bireysel düzeyde görev performansını olumlu yönde etkilemektedir. Temas Yoğunluğu $\mathrm{KZ}$ ve bireysel düzeyde görev performansı arasındaki ilişkide düzenleyici rol üstlenmektedir.

Üst bilişsel KZ'nın Yenilik performansı üzerine pozitif yönlü etkisine, bilgi paylaşımı kısmen aracılık etmektedir. Ayrıca Üst Bilişsel, Davranısssal ve Motivasyonal KZ'nın Bilgi Paylaşımı na etkisinde Ortak İklim, düzenleyici etkiye sahiptir.

KOBİ yöneticilerinin KZ'larının işletmenin performansına pozitif yönlü etkisinde, Girişimcilik yöneliminin aracılık rolü vardır.

Kz'nın servis iyileștirme performansına pozitif yönlü etkisinde, iş randevusunun aracılık etkisi vardır.

İlișki kalitesinin, üst bilișsel ve bilișsel KZ'nın kurumsal bașarı üzerine etkisinde kısmi, motivasyonal KZ'nın kurumsal başarı üzerine etkisinde tamamen aracılık rolü ettiği tespit edilmiştir. Davranıșsal $\mathrm{KZ}$ 'da ise aracilık yoktur.

KZ, göçmenlerin kültürlerarası uyumunu olumlu yönde etkilemekte ve bu doğrultuda ișten ayrılma niyeti azalmaktadır.

KZ, kültürel değerlerin müzakere yöntemleri üzerine etkisinde aracılık rolü üstlenmektedir.

$\mathrm{Kz}$, bilgi paylaşımın performans sürecinde önemli rol üstlenmektedir. Ancak coğrafik uzaklığın KZ'nın bilgi paylașımı üzerinde düzenleyici rolü vardır.

KZ, yaratıcılık performansı ile olumlu yönde ilişkilidir. Ayrıca ilișkisel çatışma arttığında, görev çatıșmaları ise azaldığında $\mathrm{KZ}$ ile yaratıcılık perfromansı arasındaki ilişki artmaktadır.

Tablo 6: Kültürel Zekâ Aracı Etki ile İlgili Araştırmalar

\begin{tabular}{|c|c|c|c|}
\hline YAZAR & ÖNCÜLLER & ETKİLER & SONUÇ \\
\hline $\begin{array}{l}\text { Kim \& Van Dyne } \\
\text { (2012) }\end{array}$ & Geçmiş Külttürlerarası İletişim & Liderlik Potansiyeli & $\begin{array}{l}\text { KZ, Geçmiş Kültürlerarası İletişim ve Liderlik Potansiyeli } \\
\text { arasındaki pozitif yönlü ilişkide aracılık etmektedir; aracılık etkisi } \\
\text { çoğunluğa uygulanmıştır, azınlığa değil. }\end{array}$ \\
\hline $\begin{array}{l}\text { Moon vd. } \\
(2012)\end{array}$ & $\begin{array}{l}\text { Kültürlerarası Deneyim } \\
\text { Ayrılık Öncesi Deneyim }\end{array}$ & Kültürlerarası Uyum & $\begin{array}{l}\text { Motivasyonal KZ, geçmiş uluslararası iş dışı deneyim ve ayrılık } \\
\text { öncesi eğitim ile genel ve çalışma uyumu arasındaki iliş̧kide } \\
\text { tamamen aracılık etmektedir. Bilişsel, Motivasyonal ve } \\
\text { Davranışsal KZ tamamen aracılık rolü üstlenmektedir. }\end{array}$ \\
\hline $\begin{array}{l}\text { Remhof vd. } \\
\text { (2013) }\end{array}$ & $\begin{array}{l}\text { Dil Yeteneği } \\
\text { Geçmiş Deneyim } \\
\text { Yurtdışı Ağı }\end{array}$ & Yurtdışı Çalışma Niyeti & $\begin{array}{l}\text { Bilişsel KZ, dil yeteneği ve yurtdışı çalıșma niyeti arasındaki } \\
\text { ilişkide aracılık etmektedir; KZ'nın dört boyutu da bu ilişkide } \\
\text { aracıllk rolü üstlenmektedir. Yurtdışı deneyimi ve yurtdışı çalışma } \\
\text { niyeti üzerinde ise kısmen aracılık etmektedir. }\end{array}$ \\
\hline $\begin{array}{l}\text { Remhof vd. } \\
\text { (2014) }\end{array}$ & Kişilik & Yurtdışı Çalışma Niyeti & $\begin{array}{l}\text { Motivasyonal KZ, kişilik ve yurtdışı çalışma niyeti arasındaki } \\
\text { pozitif yönlü ilişside tamamen aracılık etmektedir. }\end{array}$ \\
\hline $\begin{array}{l}\text { Lie vd. } \\
(2016)\end{array}$ & Deneyime Açıklık & İș Doyumu & $\begin{array}{l}\mathrm{KZ} \text {, deneyime açıklık ve iş doyumu arasındaki pozitif yönlü } \\
\text { ilişkide aracılık etkisine sahiptir. }\end{array}$ \\
\hline $\begin{array}{l}\text { Hu vd. } \\
\text { (2017) }\end{array}$ & Kültürlerarası Deneyim & Yaratıcılık & $\begin{array}{l}\mathrm{KZ} \text {, külttürlerarası deneyim ve yaratıcılık arasındaki ilişkide kısmen } \\
\text { aracılık rolü üstlenmektedir. }\end{array}$ \\
\hline $\begin{array}{l}\text { Korzilius vd. } \\
(2017)\end{array}$ & Çok kültürlülük & Yaratıcı İş Davranışları & $\begin{array}{l}\text { KZ dört boyutuyla, çok Kültürlülük ve Yaratıcı iş davranışı } \\
\text { arasındaki pozitif yönlü ilişside tamamen aracılık etkisine sahiptir. } \\
\text { Bilişsel KZ, diğer üç boyuttan daha az aracıllk etkisine sahiptir. }\end{array}$ \\
\hline $\begin{array}{l}\text { Lee vd. } \\
(2019)\end{array}$ & $\begin{array}{l}\text { Uluslararası Seyahat Deneyimi, } \\
\text { Kültürlerarası Sosyal İletişim }\end{array}$ & Göçmenlik İsteği & $\begin{array}{l}\mathrm{KZ} \text {, uluslararası seyahat deneyimi olanların veya çevresinde } \\
\text { kültürlerarası sosyal iletişimde bulunanların göçmenlik isteği } \\
\text { üzerine olumlu etkisinde aracılık etmektedir. }\end{array}$ \\
\hline
\end{tabular}


Tablo 7: Kültürel Zekâ Düzenleyici Etki ile İlgili Yapılan Araştırmalar

\begin{tabular}{|c|c|c|c|}
\hline YAZAR & $\begin{array}{l}\text { BAĞIMSIZ } \\
\text { DEĞISTKEN }\end{array}$ & $\begin{array}{l}\text { BAĞIMLI } \\
\text { DEĞISSKEN }\end{array}$ & SONUÇ \\
\hline $\begin{array}{l}\text { Elenkov \& Maney } \\
\text { (2009) }\end{array}$ & Liderlik & İnovasyon & $\begin{array}{l}\text { KZ, Yabanc1 liderliğin örgütsel inovasyon üzerindeki pozitif etkisini arttırırken, ürün } \\
\text { pazarı inovasyonu üzerine etkisinde etkin düzenleyici rol üstlenmemektedir. KZ’nın dört } \\
\text { boyutu da inovasyon üzerinde güçlü düzenleyici etkiye sahiptir. }\end{array}$ \\
\hline $\begin{array}{l}\text { Ramsey vd. } \\
\text { (2011) }\end{array}$ & Kurumsal Mesafe & Gerilim & $\begin{array}{l}\text { KZ, kurumsal mesafenin boyutlarının, gerilim üzerindeki normatif ve düzenleyici olumlu } \\
\text { etkisini azaltırken, kurumsal mesafenin kültürel tanısal boyutunun, gerilim üzerindeki } \\
\text { etkisini artırmıștır. }\end{array}$ \\
\hline $\begin{array}{l}\text { Wu \& Ang } \\
(2011)\end{array}$ & $\begin{array}{l}\text { Desteklenen } \\
\text { Uygulama }\end{array}$ & Alışma & $\begin{array}{l}\text { Üst bilişsel ve Bilişsel KZ, yabancılara ait desteklenen pratiğin, alışma üzerine olumlu } \\
\text { etkisini azaltırken, Motivasyonal KZ arttırmaktadır. }\end{array}$ \\
\hline $\begin{array}{l}\text { Lee, vd. } \\
\text { (2013) }\end{array}$ & Liderlik & Alışma, Performans & $\begin{array}{l}\text { KZ, dönüştürücü liderliğin, alışma ve performans üzerindeki olumlu yönde etkisini } \\
\text { arttırmaktadır. }\end{array}$ \\
\hline $\begin{array}{l}\text { Magnusson vd. } \\
\text { (2013) }\end{array}$ & Çevresel Farklılık & $\begin{array}{l}\text { Uyum, İhracat } \\
\text { Performansı }\end{array}$ & $\begin{array}{l}\text { Üst Bilişsel KZ, Pazarlama karması uyumunun ihracat performansı üzerine olumlu } \\
\text { etkisini artırmaktadır. Motivasyonal KZ, çevresel farklılığın pazarlama karması uyumu } \\
\text { üzerine pozitif yönlü etkisini arttırmaktadır. }\end{array}$ \\
\hline $\begin{array}{l}\text { Mor vd. } \\
\text { (2013) }\end{array}$ & Bakış Açısı Edinme & İşbirliği & $\begin{array}{l}\text { Üst Bilișsel KZ, Bakış açısı edinmenin işbirliği üzerine olumlu yönde etkisini } \\
\text { azaltmaktadır. }\end{array}$ \\
\hline $\begin{array}{l}\text { Presbitero } \\
(2016 b)\end{array}$ & $\begin{array}{l}\text { Kültürel Şok, Ters } \\
\text { Kültürel Şok }\end{array}$ & Uyum & $\begin{array}{l}\text { KZ, Kültürel şok ve Ters kültürel şokun öğrencilerin psikolojik ve sosyokülttürel } \\
\text { uyumlarının üzerindekini olumsuz yönde etkisini azaltmaktadır. }\end{array}$ \\
\hline $\begin{array}{l}\text { Rosenauer vd. } \\
\text { (2016) }\end{array}$ & Milliyet Çeşitliliği & $\begin{array}{l}\text { Çeşitlilik İklimi, } \\
\text { Performans }\end{array}$ & $\begin{array}{l}\text { Milliyet çeşitliliği, çeşitlilik iklimi ve performans ile, ancak grup liderlerine ait KZ ve } \\
\text { görev bağımsızlığı yüksek olduğu durumlarda olumlu yönde ilişkilidir. }\end{array}$ \\
\hline $\begin{array}{l}\text { Gölgeci vd. } \\
\text { (2017) }\end{array}$ & $\begin{array}{l}\text { Potansiyel Emme } \\
\text { Kapasitesi }\end{array}$ & Yenilikçilik & $\begin{array}{l}\text { Üst Bilişsel ve Davranışsal KZ, potansiyel emme kapasitesinin yenilikçilik üzerine } \\
\text { olumlu etkisini artırmaktadır. }\end{array}$ \\
\hline $\begin{array}{l}\text { Jie \& Harnis } \\
\text { (2017) }\end{array}$ & Bireysel Tutum & $\begin{array}{l}\text { Uluslararası } \\
\text { Girişimcilik Yönelimi }\end{array}$ & $\begin{array}{l}\mathrm{KZ} \text {, bireysel tutumun uluslararası girişimcilik yönelim üzerindeki pozitif etkisini } \\
\text { azaltmaktadır. }\end{array}$ \\
\hline $\begin{array}{l}\text { Lorenz vd. } \\
(2017)\end{array}$ & Kültürel Farklılık & $\begin{array}{l}\text { Davranışsal Uyum } \\
\text { İsteği }\end{array}$ & $\begin{array}{l}\text { Üst Bilişsel KZ, algılanan kültürel farklılığın davranışsal uyum isteği üzerine pozitif } \\
\text { etkisini arttırmaktadır. }\end{array}$ \\
\hline $\begin{array}{l}\text { Presbitero \& Quita } \\
\text { (2017) }\end{array}$ & $\begin{array}{l}\text { Kariyer Uyum } \\
\text { Yeteneği }\end{array}$ & $\begin{array}{l}\text { Denizaşırı Kariyer } \\
\text { yönelimi }\end{array}$ & $\mathrm{KZ}$, kariyer uyum yeteneğinin deniz aşırı yönelim üzerine olumlu etkisini artırmaktadır. \\
\hline $\begin{array}{l}\text { Şahin \& Gürbüz } \\
\text { (2017) }\end{array}$ & $\begin{array}{l}\text { Girişimcilik } \\
\text { Yönelimi }\end{array}$ & $\begin{array}{l}\text { Uluslararası } \\
\text { Performans }\end{array}$ & $\begin{array}{l}\text { Üstbilişsel, Bilişsel ve Motivasyonal KZ, girişimcilik yönelimi ve işletmenin uluslararası } \\
\text { performansı arasındaki ilişkiyi güçlendirmektedir. }\end{array}$ \\
\hline $\begin{array}{l}\text { Caputo vd. } \\
\text { (2018) }\end{array}$ & Kültürel Uyum & Çatışma Yönetimi & $\begin{array}{l}\mathrm{KZ} \text {, bireysel kültürel uyum ve çatışma yönetimi şekli arasındaki ilişkide düzenleyici rol } \\
\text { üstlenmektedir. }\end{array}$ \\
\hline $\begin{array}{l}\text { Presbitero \&Teng- } \\
\text { Calleja } \\
\text { (2019) }\end{array}$ & $\begin{array}{l}\text { Algılanan Kültürel } \\
\text { Farklılık }\end{array}$ & Görev Performansı & $\begin{array}{l}\mathrm{KZ} \text {, algılanan kültürel farklılığın görev performansı üzerindeki negatif yönlü etkide, } \\
\text { düzenleyici role sahiptir. }\end{array}$ \\
\hline $\begin{array}{l}\text { Haniefa\& Riani. } \\
\text { (2019) }\end{array}$ & $\begin{array}{l}\text { Etnik Taciz } \\
\text { Deneyimi }\end{array}$ & Terk Etme Niyeti & $\begin{array}{l}\mathrm{KZ} \text {, Endonezya'da çalışan yabancı kökenlilerin etnik taciz deneyimlerinin ülkeden } \\
\text { ayrılma niyetleri üzerine olumlu etkisinde azaltıcı (düzenleyici) rol üstlenmektedir. }\end{array}$ \\
\hline $\begin{array}{l}\text { Chui vd. } \\
\text { (2019) }\end{array}$ & $\begin{array}{l}\text { Ulusal Kültürel } \\
\text { Farklılık }\end{array}$ & $\begin{array}{l}\text { Uluslararası ortak } \\
\text { İnşaat Girişimi }\end{array}$ & $\begin{array}{l}\text { KZ, ulusal kültürel farklılıkların uluslararası ortak girişimler üzerine olumsuz yönde } \\
\text { etkisini azaltmaktadır. }\end{array}$ \\
\hline $\begin{array}{l}\text { Presbitero vd. } \\
\text { (2019) }\end{array}$ & $\begin{array}{l}\text { Algılanan Etik } \\
\text { Liderlik }\end{array}$ & $\begin{array}{l}\text { Bireysel Etik } \\
\text { Davranışlar }\end{array}$ & $\begin{array}{l}\text { KZ, kültürel farklılıkların olduğu gruplarda algılanan etik liderlik davranışlarının, } \\
\text { bireysel etik davranışlar üzerine etkisinde olumlu yönde düzenleyici etkiye sahiptir. }\end{array}$ \\
\hline $\begin{array}{l}\text { Ali vd. } \\
\text { (2019) }\end{array}$ & Bilgi Paylaşımı & $\begin{array}{l}\text { Bireysel ve Takım } \\
\text { Yaratıcılığı }\end{array}$ & $\begin{array}{l}\text { KZ, Yabancı çalışanların, yerli çalışanlarla bilgi paylaşımının bireysel ve takım } \\
\text { yaratıcılığına etkisinde düzenleyici role sahiptir. }\end{array}$ \\
\hline $\begin{array}{l}\text { Paparoidamis vd. } \\
\text { (2019) }\end{array}$ & $\begin{array}{l}\text { Algılanan Servis } \\
\text { Kalitesi }\end{array}$ & Müşteri Memnuniyeti & $\begin{array}{l}\mathrm{KZ} \text {, iki yabancı pazarın etkileşiminde algılanan servis kalitesinin müşteri memnuniyeti } \\
\text { üzerine olumlu yönde etkisine düzenleyici role sahiptir }\end{array}$ \\
\hline $\begin{array}{l}\text { Tekin } \\
\text { (2019) }\end{array}$ & Sosyal Zekâ & Akademik Performans & $\begin{array}{l}\text { KZ, öğrencilerin sosyal zekâlarının, akademik performansı üzerine olan etkisinde } \\
\text { düzenleyici rol üstlenmektedir. }\end{array}$ \\
\hline
\end{tabular}

yapılmış araştırmaların, aracılık rolü ile ilgili yapılan araştırmalara nazaran biraz daha fazla olduğu gözlenmektedir. Gölgeci ve arkadaşları (2017) yaptıkları araştırmada, Üst Bilişsel ve Davranışsal KZ'nın, potansiyel emme kapasitesinin yenilikçilik üzerine olumlu etkisini artırdığını tespit etmişlerdir. Şahin ve Gürbüz (2017) ise Üstbilişsel, Bilişsel ve Motivasyonal KZ'nın, girişimcilik yönelimi ve işletmenin uluslararası performansı arasındaki ilişkiyi güçlendirdiğini ortaya koymuştur. Ali, Ali, Leal-Rodriguez ve arkadaşları (2019) ise yaptıkları araştırmada, KZ'nın, yabancı çalışanların yerli çalışanlarla bilgi paylaşımının, bireysel ve takım yaratıcılığına etkisinde düzenleyici rol üstlendiğini tespit etmişlerdir. Son olarak Tekin (2019) ise KZ'nın, öğrencilerin sosyal zekâlarının akademik performansı üzerine olan etkisinde düzenleyici rol üstlendiğini ortaya koymuştur.

\subsection{Kültürel Zekâ Nitel Araștırmalar}

KZ ile ilgili nitel araştırmalar, yerli veya yabancı literatürde yapılan incelemelerde, nicel yaklaşımlara kıyasla oldukça az olduğu gözlenmiștir. Yerli ve yabanc1 literatürde KZ'ile ilgili yapılan nitel araştırmalar Tablo 8'de görülmektedir. Nitel araştırmalar incelendiğinde, veri toplama 
tekniklerinin genelde mülakat yöntemi ile yapıldığ gözlenmektedir. Diğer yandan, örnek olay ve inceleme yöntemleri de KZ nitel çalışmalarında sıkça rastlanan veri toplama tekniklerinin arasında yerini almaktadır. İçerik analizi yönteminin ise KZ nitel çalışma alanında daha zayıf kaldığı söylebilir.

Tablo 8'e göre kültürlerarası etkili liderlik (Deng \& Gibson, 2009), kültürel farklılık (De Ramirez, 2015 ; Gregory, Prifling \& Beck, 2009; Kaufman \& HwAng, 2015), farklılıkların yönetimine (Yeşil,
2009), hedef oryantasyonu öyküleme (Gertsen \& Soderberg, 2010), yabancıların başarısı (Lee, 2010), işletmenin ana rekabat kaynakları (Capatina vd., 2011), kültürlerarası liderlik (Ersoy, 2014), uluslararas1 deneyim (Ott \& Michailova, 2018; Ott \& Ishakova, 2019) gibi konuların KZ ile ilişkisinin nitel araştırma yöntemleri ile incelendiği ve genelde kültürel zekanın söz konusu kavramlarla olumlu ilişkiler içerisinde olduğu gözlenmektedir.

Yerli literatürde KZ konusunun bazı araştırmacılar

Tablo 8: Kültürel Zekâ ile İlgili Yapılan Nitel Araştırmalar

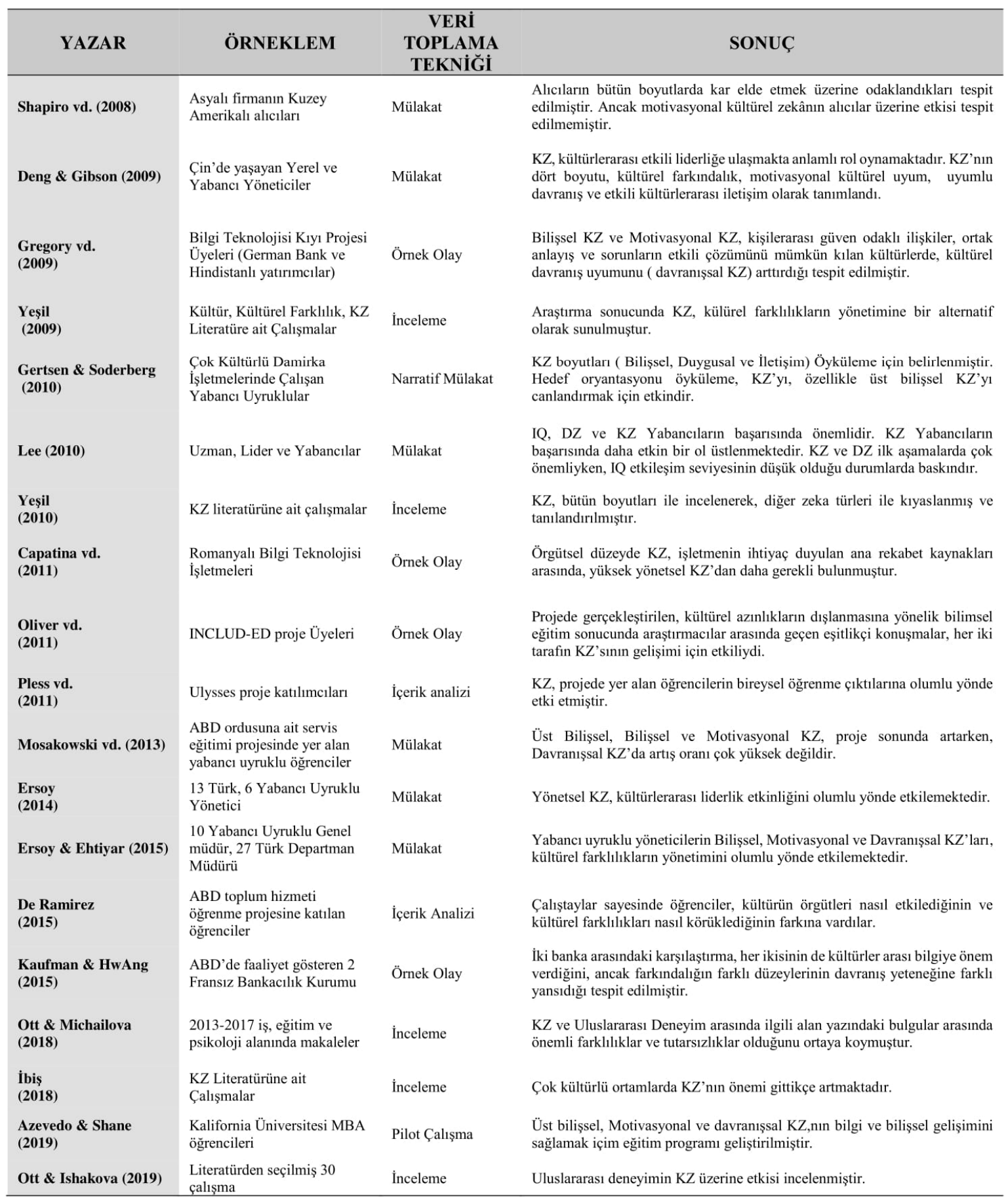


tarafından nitel araştırma yöntemleri ile incelendiği gözlenmektedir. Yeșil (2009, 2010) KZ konusunu diğer zeka türleri ile kıyaslayarak tanımlamış ve kültürel farklılıkların yönetimine bir alternatif olarak savunmuştur. Ersoy (2014) mülakat yöntemi ile yaptığ 1 ve 13 Türk, 6 Yabanc1 Uyruklu Yöneticinin yer aldığı araştırmasında, Yönetsel KZ'nın, kültürlerarası liderlik etkinliğini olumlu yönde etkilediğini tespit etmiştir. Yine Ersoy ve Ehtiyar (2015), örneklemi 10 yabancı uyruklu genel müdür ve 27 Türk departman müdüründen oluşan araştırmalarında, yabancı uyruklu yöneticilerin Bilişsel, Motivasyonal ve Davranışsal KZ'larının, kültürel farklılıkların yönetimini olumlu yönde etkilediğini ortaya koymuşlardır. İbiş (2018) ise yaptığı inceleme çalışmasında, çokkültürlü ortamlarda KZ'nın öneminin gittikçe arttığını savunmuştur (bkz. Tablo 8).

\section{SONUÇ VE ÖNERILER}

Çalışmanın başında KZ kavramının öneminin arttığı ve aynı doğrultuda kavramla ilgili yapılan araştırmaların da günden güne arttığından bahsedilmişti. Çalışmada elde edilen sonuçlar genel anlamda ilk olarak, yerli ve yabancı literatürde KZ ile ilgili araştırmaların yıllara göre artış gösterdiğini ortaya koymaktadır (Bkz. Tablo 2, Tablo 3, Tablo 4, Tablo 5, Tablo 6, Tablo 7, Tablo 8). Diğer yandan çalışmada incelenen araştırmalar, yerli literatürde KZ ile ilgili yapılan araştırmaların kısıtlı kaldığını göstermektedir (bkz. Tablo 9). Tablo 9, çalışmada incelenen araştırmaların, "Yayın Alanı" ve "Çalışma Alanı" doğrultusunda dağılımını göstermektedir. Bu doğrultuda, KZ ile ilgili gerek yerli gerekse yabancı literatürde en çok araştırmanın Doğrudan Etki Yöntemi ile ilişskisel olarak incelendiğini göstermektedir (36). Diğer yandan, Doğrudan Olmayan Etki (29) ve Düzenleyici Etki (20) Yöntemleri ile incelenen araştırmaların da yoğun durumda olduğunu söylemek mümkündür. Ancak, Aracı Etki Yöntemi ile incelenen araştırmaların sayısının oldukça az olduğu gözlenmektedir (12). Öyle ki, KZ konusu, yerli literatürde aracılık modeli ile yalnızca 1 çalışmada yer almıştır (Şahin \& Gürbüz, 2014).

Çalışmada yapılan kavramsal incelemelerin sonucu, öncelikle KZ ölçeğinin ilgili alan yazında, kısa formu (Short Form Measure Of Cultural Intelligence, SFCQ), Ticari Kültürel Zeka formu (Business Cultural intelligence Quotient, BCIQ), İki Faktörlü formu (Bi-Factor Model of CQ) ve Çapraz Örgütsel formunun (Cross-organizational cultural intelligence, COCI) bulunduğunu göstermektedir. Ayrıca, yerli literatürde KZ ölçeğinin Türkçe uyarlaması da bulunmaktadır (Arastaman, 2018; İlhan \& Çetin, 2014a; Şahin vd., 2013a). İlişkisel inceleme sonuçları ise KZ'nın, Kültürlerarası Etkinlik (Guðmundsdóttir, 2015; Huff vd., 2014; Lin vd., 2012; Shu vd., 2017; Zhang \& Oczkowski, 2016), Performans (Görev performansı, iş performans1, lider performans1, takım performans1) (Groves \& Feyerherm, 2011; Jyoti \& Kour, 2015; Malek \& Budwar, 2013; Presbitero, 2016a; Presbitero \& Toledano, 2018; Şahin \& Gürbüz, 2012; Wang, 2016, Wang vd. 2017), Kültürel Farklılık (De Ramirez ,2015 ; Gregory vd., 2009; Kaufman \& HwAng, 2015), Kültürlerarası Deneyim (Crowne, 2008; Kurpis \& Hunter, 2017; Li vd.,2013; Moon vd.,2012; Pekerti \& Arli, 2017 ; Schwarzenthal vd., 2017) ve Kişilik Özellikleri (Ang vd. 2006; Depaula vd. 2016; Harrison, 2012; Kement vd. 2019; Li vd., 2016; Şahin vd. ,2013b) gibi kavramlarla sı $\mathrm{s} 1 \mathrm{k}$ ilişkilendirildiğini göstermektedir.

$\mathrm{Bu}$ çalışmada yerli ve yabancı literatürde $\mathrm{KZ}$ ile ilgili 2003-2020 yılları arasında yapılmış araştırmaların incelenmesi hedeflenmiştir. Çalışmanın inceleme alanının genişliği, çalışmada yer alan araştırmaların derinlemesine incelenmesini kısıtlamıştır. Araştırmalar yalnızca, yöntemleri, değişkenleri ve kısa kısa sonuçları bağlamında değerlendirilmiştir. Bundan sonra yapılacak araştırmalarda, çalışma alanının kısıtlanması, daha derinlemesine inceleme yapma olanağ 1 sağlayacaktır. Diğer yandan, çalışma, KZ ile ilgili yapılacak gelecek araştırmalar için ilgili alan yazın taraması niteliği taşımaktadır. Aynı zamanda, yerli

Tablo 9: Çalışmada Yer Alan Araştırmaların Dağılımı

\begin{tabular}{|c|c|c|c|c|c|c|c|c|c|}
\hline \multicolumn{2}{|c|}{ Çalıșma Alanı } & $\begin{array}{c}\text { KZ'nın } \\
\text { Ölçülmesi }\end{array}$ & $\begin{array}{c}\text { KZ'nın } \\
\text { Öncïlleri }\end{array}$ & $\begin{array}{c}\text { KZ } \\
\text { Doğrudan } \\
\text { Etki }\end{array}$ & $\begin{array}{c}\text { KZ } \\
\text { Doğrudan } \\
\text { Olmayan } \\
\text { Etki }\end{array}$ & $\begin{array}{c}\text { KZ } \\
\text { Aracı } \\
\text { Etki }\end{array}$ & $\begin{array}{c}\text { KZ } \\
\text { Düzenleyici } \\
\text { Etki }\end{array}$ & $\begin{array}{c}\text { KZ } \\
\text { Nitel } \\
\text { Araştırmalar }\end{array}$ & TOPLAM \\
\hline $\begin{array}{l}\text { Yayın } \\
\text { Alanı }\end{array}$ & Yerli & 3 & 5 & 10 & 1 & 1 & 3 & 5 & 28 \\
\cline { 2 - 11 } & Yabancı & 14 & 14 & 26 & 28 & 11 & 17 & 14 & 124 \\
\hline
\end{tabular}


ve yabancı literatürde KZ ile ilgili araştırmaların kısıtlı bulunduğu alanlar, gelecek araştırmalar için çalışma konusu olarak önerilebilmektedir.

\section{ETİK BEYANATI}

Destek Bilgisi: Bu çalışma, kamu, ticari veya kar amacı gütmeyen kuruluşlar gibi herhangi bir organizasyondan destek almamıştır.

Çıkar Çatışması: Tüm yazarlar adına, sorumlu yazar çıkar çatışması olmadığını belirtir.

Etik Onayı: İnsan katılımcıları içeren çalışmalarda gerçekleştirilen tüm prosedürler, kurumsal ve / veya ulusal araştırma komitesinin etik standartlarına ve 1964 Helsinki deklarasyonuna ve daha sonraki değişikliklerine veya karşılaştırılabilir etik standartlara uygundur.

\section{KAYNAKÇA}

Abaslı, A. \& Polat, Ş. (2019). Öğrencilerin Kültürlerarası Duyarlılık ve Kültürel Zekâya İlişkin Görüşlerinin İncelenmesi. Anemon Muş Alparslan Üniversitesi Sosyal Bilimler Dergisi, 7(1) 193-202.

Adair, W. L., Buchan, N. R., Chen, X. P. \& Liu, D. (2016). A model of communication context and measure of context dependence. Academy of Management Discoveries, 2(2), 198-217.

Adler, N. J. (2002). International Dimensions of Organizational Behavior (4th ed.). Mason,USA: Thomason, South-Western. 99, 23-36.

Akhal, K. \& Liu, S. (2019). Cultural intelligence effects on expatriates' adjustment and turnover intentions in Mainland China. Management Research Review, 42(7), 818-836.

AL-Dossary, S. A. (2016). Psychometric properties of the cultural intelligence scale in a Saudi Arabian context. International Journal of Selection and Assessment, 24(4), 305-311.

Ali, I., Ali, M., Leal-Rodriguez, A. L. vd. (2019). The role of knowledge spillovers and cultural intelligence in enhancing expatriate employees' individual and team creativity. Journal of Business Research, 101, 561-573.

Alon, I., Boulanger, M., Ann,E. J. vd. (2018). Business Cultural Intelligence Quotient: A Five-Country Study. Thunderbird International Business Review, 60(3), 237-250.

Alon, I., Boulanger, M., Meyers, J. \& Taras, V. (2016). The development and validation of the business cultural intelligence quotient. Cross Cultural \& Strategic Management, 23(1), 78-100.

Andresen, M. \& Bergdolt, F. (2016). A systematic literature review on the definitions of global mindset and cultural intelligence-merging two different research streams. The International Journal of Human Resource Management, 28(1), 170-195.

Ang, S. Dyne, L. V., Koh, C. \& Chandrasekar, N. A. (2007). Cultural Intelligence: Its Measurement and Effects on Cultural Judgment and Decision Making, Cultural Adaptation, and Task Performance. Management and Organization Review, 3(3), 335371.

Ang, S., Rockstuhl, T. \& Tan, M. L. (2015). Cultural intelligence and competencies. In J. B. Wright (Ed.). International Encyclopedia of The Social \& Behavioral Sciences, ss. 433-439. (2nd ed.). Oxford: Elsevier.

Ang, S., Van Dyne, L. \& Koh, C. (2006). Personality correlates of the four-factor model of cultural 
intelligence. Group \& Organization Management, 31(1), 100-123.

Ang, S., Van Dyne, L., Koh, C., Ng, K.-Y., Templer, K. J., Tay, C. \& Chandrasekar, N. A. (2007). Cultural intelligence: Its measurement and effects on cultural judgment and decision making, cultural adaptation and task performance. Management and Organization Review, 3, 335-371.

Ang, S. \& Van Dyne, L. (2008). Conceptualization of Cultural Intelligence: Definition, Distinctiveness, and Nomological Network. (içinde) S. Ang \& L. Van Dyne (Ed.), Handbook of Cultural Intelligence: Theory, Measurement, and Applications (ss. 3-15). Armonk, NY: M E Sharpe.

Arastaman, G. (2018). Kültürel Zeka Ölçeğinin (KZÖ) Türk Akademisyenler Üzerinde Geçerlik ve Güvenirlik Çalışması. Yüksekögretim Dergisi, 8(1), 18.

Aslam, U., Ilyas, M., Imran, M. K. \& Ur Rahman, U. (2016). Intelligence and its impact on managerial effectiveness and career success (evidence from insurance sector of Pakistan). Journal of Management Development, 35(4), 505-516.

Azevedo, A. \& Shane, M. J. (2019). A new training program in developing cultural intelligence can also improve innovative work behavior and resilience: A longitudinal pilot study of graduate students and professional employee. International Journal of Management, 17(3).

Bernardo, A. B. \& Presbitero, A. (2017). Belief in polyculturalism and cultural intelligence: Individualand country-level differences. Personality and Individual Differences, 119, 307-310.

Berraies, S. (2019). Effect of middle managers' cultural intelligence on firms' innovation performance Knowledge sharing as mediator and collaborative climate as moderator. Personnel Review.

Bhaskar-Shrinivas, P., Harrison, D. A., Shaffer, M. A. \& Luk, D. M. (2005). Input-based and time-based models of international adjustment: Meta-analytic evidence and theoretical extensions. Academy of Management Journal, 48, 257-281

Bhawuk, D. \& Brislin, R. (2000). Cross-cultural training. A review. Appl. Psychol. 49, 162-91

Black, J. S., Gregerson, J. B., Mendenhall, M. E. \& Stroh, L. K. (1999). Globalizing people through internationalassignments. Reading, MA: AddisonWesley

Black, J. S. \& Mendenhall, M. (1990). Cross-cultural training effectiveness: A review and a theoretical framework for future research. Academy of Management Review, 15, 113-136.
Bücker, J. (2014). Cultural intelligence as a key construct for global talent management. In A. Al Ariss (Ed.). Global talent management: Challenges, strategies and opportunities, pp.65-78. Cham, Switzerland: Springer.

Bücker, J., Furrer, O. \& Weem, P. T. (2016). Robustness and cross-cultural equivalence of the cultural intelligence scale (CQS). Journal of Global Mobility: The Home of Expatriate Management Research, 4(3), 300-325.

Bücker, J., Furrer, O., Poutsma, E. \& Buyens, D. (2014). The impact of cultural intelligence on communication effectiveness, job satisfaction, and anxiety for Chinese host country managers working for foreign multinationals. The International Journal of Human Resource Management, 25(14), 2068-2087.

Büyükbeşe, T. \& Yıldız, B. (2016). Kültürel Zekanın Yaşam Doyumu Üzerine etkisi. Uluslararası Sosyal Araştırmalar Dergisi, 9(45).

Caligiuri, P. M. (2006). Performance measurement in a cross-national context. (içinde) W. Bennett, C. E. Lance \& D. J. Woehr (Ed.). Performance measurement: Current perspectives and future challenges (ss. 227-243). Mahwah, NJ: Erlbaum.

Caligiuri, P. M., Hyland, M. A. M., Joshi, A. \& Bross, A. S. (1998). Testing a theoretical model for examining the relationship of family adjustment and expatrite's work adjustment. Journal of Applied Psychology, 53, 67-88.

Capatina, A., Micu, A., Lukacs, E., Micu, A. E., Cristache, N. \& Susanu, I. (2011). Opportunities for a Romanian company's business development in countries with cultural intelligence compatibility. African Journal of Business Management, 5(30), 11946-11954.

Caputo, A., Ayoko, O. B., Amoo, N. \& Menke, C. (2019) The relationship between cultural values, cultural intelligence and negotiation styles. Journal of Business Research, 99, 23(36).

Caputo, A., Ayoko, O. B. \& Amoo, N. (2018). The moderating role of cultural intelligence in the relationship between cultural orientations and conflict management styles. Journal of Business Research, 89, 10-20.

Charas, S. (2015). Improving corporate performance by enhancing team dynamics at the board level. International Journal of Disclosure and Governance, 12(2), 107-131.

Charoensukmongkol, P. (2015). Cultural intelligence of entrepreneurs and international network ties: The case of small and medium manufacturing firms in Thailand. Management Research Review, 38(4), 421436. 
Charoensukmongkol, P. (2016). Cultural intelligence and export performance of small and medium enterprises in Thailand: Mediating roles of organizational capabilities. International Small Business Journal, 34(1), 105-122.

Chen, A. S. Y. (2015). CQ at work and the impact of intercultural training: An empirical test among foreign laborers. International Journal of Intercultural Relations, 47, 101-112.

Chen, A. S. Y., Lin, Y. C. \& Sawangpattanakul, A. (2011). The relationship between cultural intelligence and performance with the mediating effect of culture shock: A case from Philippine laborers in Taiwan. International Journal of Intercultural Relations, 35(2), 246-258.

Chui, Z., Liu, J. Xia, B. vd. (2019). Beyond national culture difference The role of cultural intelligence in cooperation within international construction joint ventures and insights from Chinese companies. Engineering Construction and Architectural Management, 26(7), pp. 1476-1497.

Collins, N., Chou, Y. M., Warner, M. \& Rowley, C. (2017). Human factors in East Asian virtual teamwork: A comparative study of Indonesia, Taiwan and Vietnam. The International Journal of Human Resource Management, 28(10), 1475-1498.

Costers, A., Van Vaerenbergh, Y. \& Van den Broeck, A. (2019). How to boost frontline employee service recovery performance: the role of cultural intelligence. Service Business, 13(3), 581-602.

Crowne, K. A. (2008). What leads to cultural intelligence? Business Horizons, 51(5), 391-399.

Crowne, K. A. (2013). An empirical analysis of three intelligences. Canadian Journal of Behavioural Science/Revue canadienne des sciences $d u$ comportement, 45(2), 105-114.

Çalışkan, S. C., Ünal, Z. M., Kalafatoğlu, Y., Üçler, C. \& Akün, F. A. (2015). Yöneticilerin Algılanan Kültürel Zekâsı, Çalışanın Farklılık İklimi Algısı, Gelişime Açıklık ve Örgütsel Sinisizm Etkileşimi Üzerine Turizm Sektöründe Bir Araştırma. İşv ve Insan Dergisi I The Journal of Human and Work, 2(1), 1-11.

De Ramirez, C. K. (2015). Strategy and action: Assessing student-led culture workshops within the professions. Foreign Language Annals, 48(1), 56-67.

Delpechitre, D., \& Baker, D. S. (2017). Cross-cultural selling: Examining the importance of cultural intelligence in sales education. Journal of Marketing Education, 39(2), 94-108.

Deng, L. \& Gibson, P. (2009). Mapping and modeling the capacities that underlie effective cross-cultural leadership: An interpretive study with practical outcomes. Cross Cultural Management: An International Journal, 16(4), 347-366.

Depaula, P. D., Azzollini, S. C., Cosentino, A. C. \& Castillo, S. E. (2016). Personality, character strengths and cultural intelligence: "Extraversion" or "openness" as further factors associated to the cultural skills. Avances en Psicología Latinoamericana, 34(2), 415-436.

Earley, P. C. \& Mosakowski, E.(2004). Cultural Intelligence. Harvard Business Review.

Earley, P. C. \& Ang, S. (2003). Cultural intelligence: Individual interactions across cultures. PaloAlto: Stanford University Press.

Earley, P. C. \& Peterson, R. S. (2004). The elusive cultural chameleon: Cultural intelligence as a new approach to intercultural training for the global manager. Academy of Management Learning and Education, 3, 100-115.

Ekici Yaşar, F. (2017). Okul Öncesi Öğretmen Adaylarının Kültürel Zeka Düzeyleri ve Çok Kültürlü Eğitime Yönelik Tutumları. Kastamonu Eğitim Dergisi, 25(5), 1941-1956.

Elenkov, D. S. \& Manev, I. M. (2009). Senior expatriate leadership's effects on innovation and the role of cultural intelligence. Journal of World Business, 44(4), 357-369.

Erez, M. \& Early, P. C. (1993). Culture, Self-identity and Work. Oxford University Press, New York, NY.

Ersoy, A. \& Ehtiyar, R. (2015). Kültürel Farklılıkların Yönetiminde Kültürel Zekânın Rolü: Türk ve Yabanc1 Yöneticiler Üzerine Bir Araştırma. Anatolia: Turizm Araştırmaları Dergisi, 26(1), 42 60 .

Ersoy, A. (2014). The Role of Cultural Intelligence in Cross-Cultural Leadership Effectiveness: A Qualitative Study in the Hospitality Industry. Journal of Yasar University, 35(9), 6099-6108.

Fang. F, Schei. V. \& Selart, M. (2018). Hype or hope? A new look at the research on cultural intelligence. International Journal of Intercultural Relations, 66, 148-171.

Flavell, J. H. (1979). Meta-cognition and cogntive monitoring: A new area of cognitive inquiry. American Psychologist, 34, 906-911.

Frias-Jamilena, D. M., Sabiote-Ortiz, C. M., MartinSantana, J. D. vd. (2018). Antecedents and consequences of cultural intelligence in tourism. Journal of Destination Marketing \& Management, 8, 350-358.

Gertsen, M. C. \& Søderberg, A. M. (2010). Expatriate stories about cultural encounters-A narrative 
approach to cultural learning processes in multinational companies. Scandinavian Journal of Management, 26(3), 248-257.

Gezer, M. \& Şahin, İ. F. (2017). Çok Kültürlü Eğitime Yönelik Tutum ve Kültürel Zeka Arasındaki İlişkinin Yem ile İncelenmesi. Eastern Geographical Review, 22(38), 173-188

Gonçalves, G., Reis, M., Sousa, C., Santos, J. \& Orgambídez-Ramos, A. (2015). The effect of multicultural experience in conflicts management styles: Mediation of cultural intelligence and selfmonitoring. Journal of Spatial and Organizational Dynamics, 3(1), 4-21.

Gökten, Ö. \& Emil, S. (2019). Erasmus Programı'nın Üniversite Öğrencilerinin Kültürel Zekaları Üzerindeki Etkisinin İncelenmesi. Hacettepe University Journal of Education, 34(3), 769-785.

Gölgeci, I., Swiatowiec-Szczepanska, J. \& Raczkowski, K. (2017). How does cultural intelligence influence the relationships between potential and realised absorptive capacity and innovativeness? Evidence from Poland. Technology Analysis \& Strategic Management, 29(8), 857-871.

Grand, J. A., Golubovich, J., Ryan, A. M. \& Schmitt, N. (2013). The detection and influence of problematic item content in ability tests: An examination of sensitivity review practices for personnel selection test development. Organizational Behavior and Human Decision Processes, 121(2), 158-173.

Gregory, R., Prifling, M. \& Beck, R. (2009). The role of cultural intelligence for the emergence of negotiated culture in IT offshore outsourcing projects. Information Technology \& People, 22(3), 223-241.

Groves, K. S. \& Feyerherm, A. E. (2011). Leader cultural intelligence in context: Testing the moderating effects of team cultural diversity on leader and team performance. Group \& Organization Management, $36(5), 535-566$.

Guðmundsdóttir, S. (2015). Nordic expatriates in the US: The relationship between cultural intelligence and adjustment. International Journal of Intercultural Relations, 47, 175-186.

Gudykunst, W. B., Ting-Toomey, S. \& Chua, E. (1988). Culture and interpersonal communication. Newbury Park, Calif: Sage.

Gustomo, A., Putranto, N. A. R., Ghazali, A. vd. (2018). Designing Effective Field Trip Activities to Develop Stundents' Cultural Intelligence. International Journal of Business and Society, 19(1), 195-208.

Hall, W. (1959). Managing Cultures. John Wiley \& Sons Ltd, New York.
Haniefa, T. \& Riani, A. L. (2019) The Moderating Role of Cultural Intelligence on the Effect of Ethnic Harassment Experience on Employees' Intention to Leave in Indonesia. International Journal of Business, 24(3), 296-307.

Harrison, N. (2012). Investigating theimpact of personality andearly life experiences on intercultural interaction in internationalised universities. International Journal of Intercultural Relations, 36(2), 224-237.

Hofstede, G. (1991). Culture and organizations: Software of the mind. London: McGrawHill.

Holtbrügge, D. \& Engelhard, F. (2016). Study stays abroad. Individual motivations, cultural intelligence and the mediating role of cultural boundary spanning. Academy of Management Learning \& Education, 15(3), 435-455.

House, R. J., Hanges, P. J., Javidan, M., Dorfman, P. W. \& Gupta, V. (2004). Culture, leadership, and organizations: The GLOBE study of 62 societies. Palo Alto, CA: Sage.

Hu, S., Gu, J., Liu, H. \& Huang, Q. (2017). The moderating role of social media usage in the relationship among multicultural experiences, cultural intelligence, and individual creativity. Information Technology \& People, 30(2), 265-281.

Hu, S., Liu, H. \& Gu, J. (2018). What role does selfefficacy play in developing cultural intelligence from social media usage? Electronic Commerce Reserach and Application, 28, 172-180.

Huff, K. C., Song, P. \& Gresch, E. B. (2014). Cultural intelligence, personality, and cross-cultural adjustment: A study of expatriates in Japan. International Journal of Intercultural Relations, 38 , 151-157.

İbiş, T. (2018). Çok Kültürlülük ve Kültürel Zeka. Yeni Düşünceler, 10, 20-35

İlhan, M. \& Çetin, B. (2014a). Kültürel Zekâ Ölçeği'nin Türkçe Formunun Geçerlik ve Güvenirlik Çalışması. Hacettepe University Journal of Education, 29(2), 94114.

İlhan, M. \& Çetin, B. (2014b). Sosyal ve Kültürel Zekâ Arasındaki İlişsinin Yapısal Eşitlik Modeli ile İncelenmesi. Turkish Journal of Education, 3(2), 415.

Jiang, Z., Le, H. \& Gollan, P. J. (2018). Cultural intelligence and voice behavior among migrant workers: the mediating role of leader-member Exchange. International Journal of Human resource Management, 29(5), 1082-1112.

Jie, S. \& Harms, R. (2017). Cross-cultural competences and international entrepreneurial intention: A study 
on entrepreneurship education. Education Research International. https://doi.org/10.1155/2017/9042132

Joardar, A., Kostova, T. \& Ravlin, E. C. (2007). An experimental study of the acceptance of a foreign newcomer into a workgroup. Journal of International Management, 13(4), 513-537.

Johnson, J., Lenartowicz, T. \& Apud, S. (2006). Crosscultural competence in international business: toward a definition and a model. Journal of International Business Studies, 37(4), 525-543.

Jyoti, J. \& Kour, S. (2015). Assessing the cultural intelligence andtask performance equation: Mediating role ofcultural adjustment. Cross Cultural Management, 22(2), 236-258.

Jyoti, J. \& Kour, S. (2017). Factors affecting cultural intelligence and its impact on job performance: Role of cross-cultural adjustment, experience and perceived social support. Personnel Review, 46(4), 767-791.

Kadam, R., Rao, S., Abdul, W. K. vd. (2019). Impact of cultural intelligence on SME performance The mediating effect of entrepreneurial orientation. Journal of Organizational Effectiveness-People and Performance, 6(3), 161-185.

Kanten, P. (2014). Kültürel zekânın kariyer yetkinlikleri ve müşteri odaklı hizmet davranışları üzerindeki etkisi. Istanbul University Journal of the School of Business Administration, 43(1), 100-119.

Kaufman, S. R. \& Hwang, A. (2015). Cultural intelligence and mindfulness in two French banks operating in the US environment. Management Research Review, 38(9), 930-951.

Kement, Ü., Çavuşoğlu, S. \& Uslu, A. (2019). Turizm Eğitimi Gören Öğrencilerin Kişilik Özelliklerinin Kültürel Zekâ Düzeylerine Etkisi. Anatolia: Turizm Araştırmaları Dergisi, 30(1), 57- 68.

Khani, A., Etebarian, A. \& Abzari, M. (2011). The relationship between cultural intelligence and group effectiveness in Mobarakeh steel company. African Journal of Business Management, 5(17), 7507-7510.

Kim, Y. J. \& Van Dyne, L. (2012). Cultural intelligence and international leadership potential: The importance of contact for members of the majority. Applied Psychology, 61(2), 272-294.

Kirkman, B. L., Tesluk, P. E. \& Rosen, B. (2001). Assessing the incremental validity of team consensus ratings over aggregation of individual-level data in predicting team effectiveness. Personnel Psychology, $54,645-667$.

Klafehn, J., Li, C. \& Chiu, C. Y. (2013). To know or not to know, is that the question? Exploring the role and assessment of metacognition in cross-cultural contexts. Journal of Cross-Cultural Psychology, 44(6), 963-991.

Korzilius, H., Bücker, J. J. \& Beerlage, S. (2017). Multiculturalism and innovative work behavior: The mediating role of cultural intelligence. International Journal of Intercultural Relations, 56, 13-24.

Koyuncu, Ü. \& Akdöl, B. (2019). Kültürel Zekanın Girişimcilik Yönelimine Etkisi: Laleli Pazarındaki Mikro Ölçekli İşletmelerde Bir Araştırma. Journal of Management \& Economics, 26(3), 955-968.

Kraimer, M. L., Wayne, S. J. \& Jaworski, R. A. (2001). Sources of support and expatriate performance: The mediation role of expatriate adjustment. Personnel Psychology, 54, 71-99.

Kulakoğlu N. D. \& Topaloğlu, C. (2017). Kültürel Farklılıkların Yönetimi Sürecinde Kültürel Zekânın Etkinliği. Anatolia: Turizm Araştırmaları Dergisi, 28(1).

Kurpis, L. H. \& Hunter, J. (2017). Developing students' cultural intelligence through an experiential learning activity: A cross-cultural consumer behavior interview. Journal of Marketing Education, 39(1), $30-46$.

Landis, F. C., Gargas, A. \& Givnish, T. J. (2004). Blackwell Publishing, Ltd. Relationships among arbuscular mycorrhizal fungi, vascular plants and environmental conditions in oak savannas, Department of Botany, University of WisconsinMadison, Madison, WI 53706, USA, New Phytologist, 164, 493-504

Lee, J., Webera, M. R. \& Rivera, D. (2019). A sociocultural perspective on expatriation willingness: The mediating role of cultural intelligence. Journal of Hospitality Marketing \& Management, 28(1), 124145.

Lee, L. Y. (2010). Multiple intelligences and the success of expatriation: The roles of contingency variables. African Journal of Business Management, 4(17), 3793-3894.

Lee, L. Y. \& Kartika, N. (2014). The influence of individual, family, and social capital factors on expatriate adjustment and performance: The moderating effect of psychology contract and organizational support. Expert Systems With Applications, 41(11), 5483-5494.

Lee, L. Y. \& Sukoco, B. M. (2010). The effects of cultural intelligence on expatriate performance: The moderating effects of international experience. The International Journal of Human Resource Management, 21(7), 963-981. 
Lee, L. Y., Veasna, S. \& Sukoco, B. M. (2014). The antecedents of cultural effectiveness of expatriation: Moderating effects of psychological contracts. Asia Pacific Journal of Human Resources, 52(2), 215-233.

Lee, L. Y., Veasna, S. \& Wu, W. Y. (2013). The effects of social support and transformational leadership on expatriate adjustment and performance: The moderating roles of socialization experience and cultural intelligence. Career Development International, 18(4), 377-415.

Leung, K., Ang, S. \& Tan, M. L. (2014). Intercultural competence. Annual Review of Organizational Psychology and Organizational Behavior, 1(1), 489519.

Li, M., Mobley, W. H. \& Kelly, A. (2013). When do global leaders learn best to develop cultural intelligence? An investigation of the moderating role of experiential learning style. Academy of Management Learning \& Education, 12(1), 32-50.

Li, M., Mobley, W. H. \& Kelly, A. (2016). Linking personality to cultural intelligence: An interactive effect of openness and agreeableness. Personality and Individual Differences, 89, 105-110.

Lie, D., Suyasa, P. T. \& Wijaya, E. (2016). The mediating role of cultural intelligence in the relationship between the openness to experience personality trait and job satisfaction among expatriates. Makara Human Behaviour Studies in Asia, 20(1), 46-56.

Lievens, F., Harris, M. M., van Keer, E. \& Bisqueret, C. (2003). Predicting cross-cultural training performance: The validity of personality, cognitive abilityand dimensions measured by an assessment center and a behaviour description interview. Journal of Applied Psychology, 88, 476-489

Lin, Y. C., Chen, A. S. Y. \& Song, Y. C. (2012). Does your intelligence help to survive in a foreign jungle? The effects of cultural intelligence and emotional intelligence on cross-cultural adjustment. International Journal of Intercultural Relations, 36(4), 541-552.

Lisak, A. \& Erez, M. (2015). Leadership emergence in multicultural teams: The power of global characteristics. Journal of World Business, 50(1), 314.

Lorenz, M. P., Ramsey, J. R. \& Richey, R. G. (2018). Expatriates' international opportunity recognition and innovativeness: The role of metacognitive and cognitive cultural intelligence. Journal of World Business, 53(2), 222-236.

Lorenz, M. P., Ramsey, J. R., Tariq, A. \& Morrell, D. L. (2017). Service excellence in the light of cultural diversity: The impact of metacognitive cultural intelligence. Journal of Service Theory and Practice, 27(2), 475-495.

Magnusson, P., Westjohn, S. A., Semenov, A. V., Randrianasolo, A. A. \& Zdravkovic, S. (2013). The role of cultural intelligence in marketing adaptation and export performance. Journal of International Marketing, 21(4), 44-61.

Malek, M. A. \& Budhwar, P. (2013). Cultural intelligence as a predictor of expatriate adjustment and performance in Malaysia. Journal of World Business, $48(2), 222-231$.

Mendenhall, M., ve Oddou, G. (1985). The dimensions of expatriate acculturation: A review. Academy of Management Review, 10(1), 39-47.

Moon, H. K., Choi, B. K. \& Jung, J. S. (2012). Previous international experience, cross-cultural training, and expatriates' cross-cultural adjustment: Effects of cultural intelligence and goal orientation. Human Resource Development Quarterly, 23(3), 285-330.

Moon, T. (2010a). Emotional intelligence correlates of the four-factor model of cultural intelligence. Journal of Managerial Psychology, 25(8), 876-898. http://dx.doi. org/10.1108/02683941011089134.

Moon, T. (2010b). Organizational cultural intelligence: Dynamic capability perspective. Group \& Organization Management, 35(4), 456-493. http://dx.doi.org/10. 1177/1059601110378295.

Mor, S., Morris, M. W. \& Joh, J. (2013). Identifying and training adaptive cross-cultural management skills: The crucial role of cultural metacognition. Academy of Management Learning \& Education, 12(3), 453475 .

Mosakowski, E., Calic, G. \& Earley, P. C. (2013). Cultures as learning laboratories: What makes some more effective than others? Academy of Management Learning \& Education, 12(3), 512-526.

Moyano, M., Tabernero, C., Melero, R. \& Trujillo, H. M. (2015). Spanish version of the Cultural Intelligence Scale (CQS). Revista de Psicología Social, 30(1), 182-216.

Nel, N., Nel, J. A., Adams, B. G. \& De Beer, L. T. (2015). Assessing cultural intelligence, personality and identity amongst young white Afrikaans-speaking students: A preliminary study. SA Journal of Human Resource Management, 13(1), 1-12.

Nelson, T.O. (1996). Consciousness and meta-cognition. American Psychologist, 51, 102-116.

Ng, K. Y., Van Dyne, L. \& Ang, S. (2009). From experience to experiential learning: Cultural intelligence as a learning capability for global leader development. Academy of Management Learning \& Education, 8(4), 511-526. 
Oliver, E., de Botton, L., Soler, M. \& Merrill, B. (2011). Cultural intelligence toovercome educational exclusion. Qualitative Inquiry, 17(3), 267-276.

Ones, D. S. \& Viswesvaran, C. (1997). Personality determinants in the prediction of aspects of expatriate job success. In, D. M. Saunders (Ed.) \& Z. Aycan (Vol. Ed.). New approaches to employee management. 4. Expatriate management: Theory and research (ss. 63-92). Stamford, CT: JAI Press.

Ott, D. L. \& Ishakova, M. (2019). The meaning of international experience for the development of cultural intelligence A review and critique. Critical Perspective on International Business, 15(4), 390407.

Ott, D. L. \& Michailova, S. (2018). Cultural Intelligence: A Review and New Research Avenues. International Journal of Management Reviews, 20(1), 99-119.

Paparoidamis, N. G., Huong, T. T. \& Leonidou, C. N. (2019). Building Customer Loyalty in Intercultural Service Encounters: The Role of Service Employees' Cultural Intelligence. Journal of International Marketing, 27(2), 56-75.

Pekerti, A. A. \& Arli, D. (2017). Do cultural and generational cohorts matter to ideologies and consumer ethics? A comparative study of Australians, Indonesians, and Indonesian migrants in Australia. Journal of Business Ethics, 143(2), 387-404.

Pless, N. M., Maak, T. \& Stahl, G. K. (2011). Developing responsible global leaders through international service-learning programs: The Ulysses experience. Academy of Management Learning \& Education, 10(2), 237-260.

Presbitero, A. (2016a). Cultural intelligence (CQ) in virtual, cross-cultural interactions: Generalizability of measure and links to personality dimensions and task performance. International Journal of Intercultural Relations, 50, $29-38$.

Presbitero, A. (2016b). Culture shock and reverse culture shock: The moderating role of cultural intelligence in international students' adaptation. International Journal of Intercultural Relations, 53, 28-38.

Presbitero, A. (2017). It's not all about language ability: Motivational cultural intelligence matters in call center performance. The International Journal of Human Resource Management, 28(11), 1547-1562.

Presbitero, A. \& Toledano, L. S. (2018). Global team members' performance and the roles of cross-cultural training, cultural intelligence, and contact intensity: the case of global teams in IT offshoring sector. International Journal of Human Resource Management, 29(14), 2188-2208.
Presbitero, A. \& Quita, C. (2017). Expatriate career intentions: Links to career adaptability and cultural intelligence. Journal of Vocational Behavior, 98, 118-126.

Presbitero, A., Teng-Calleja, M. (2019). Ethical leadership, team leader's cultural intelligence and ethical behavior of team members Implications for managing human resources in global teams. Personnel Review, 48(5), 1381-1392.

Putranto, N. A. R., Nuraeni, S., Gustomo, A. \& Ghazali, A. (2018). The relationship between cultural intelligence, emotional intelligence, and student performance. International Journal of Business, 23(1), 17-25.

Puyod, J. V. \& Charoensukmongkol, P. (2019). The contribution of cultural intelligence to the interaction involvement and performance of call center agents in cross-cultural communication The moderating role of work experience. Management Research Review, 42 (12), 1400-1422.

Ramsey, J. R., Leonel, J. N., Gomes, G. Z. \& Monteiro, P. R. R. (2011). Cultural intelligence's in fluence on international business travelers' stress. Cross Cultural Management: An International Journal, 18(1), 21-37.

Ramsey, J. R., Rutti, R. M., Lorenz, M. P., Barakat, L. L. \& Sant'anna, A. S. (2017). Developing global transformational leaders. Journal of World Business, 52(4), 461-473.

Remhof, S., Gunkel, M. \& Schlaegel, C. (2014). Good bye, Germany! The influence of personality and cognitive factors on the intention to work abroad. The International Journal of Human Resource Management, 25(16), 2319-2343.

Remhof, S., Gunkel, M. \& Schlägel, C. (2013). Working in the "global village":The influence of cultural intelligence on the intention to work abroad. German Journal of Human Resource Management/Zeitschrift für Personalforschung, 27(3), 224-250.

Rockstuhl, T. \& Van Dyne, L. (2018). A bi-factor theory of the four-factor model of cultural intelligence: Meta-analysis and theoretical extensions. Organizational Behavior and Human Decision Processes, 148, 124-144.

Rockstuhl, T., Seiler, S., Ang, S., Van Dyne, L. \& Annen, H. (2011). Beyond general intelligence (IQ) and emotional intelligence (EQ): The role of cultural intelligence (CQ) on cross-border leadership effectiveness in a globalized world. Journal of Social Issues, 67(4), 825-840.

Rosenauer, D., Homan, A. C., Horstmeier, C. A. \& Voelpel, S. C. (2016). Managing nationality diversity: The interactive effect of leaders' cultural intelligence 
and task interdependence. British Journal of Management, 27, 628-645.

Schlägel, C. \& Sarstedt, M. (2016). Assessing the measurement invariance of the four-dimensional cultural intelligence scale across countries: A composite model approach. European Management Journal, 34(6), 633-649.

Schwarzenthal, M., Juang, L. P., Schachner, M. K., van de Vijver, F. J. R. \& Handrick, A. (2017). From tolerance to understanding: Exploring the development of intercultural competence in multiethnic contexts from early to late adolescence. Journal of Community \& Applied Social Psychology, 27(5), 388-399.

Shaffer, M. A., Harrison, D. A., Gregersen, H., Black, J. S. \& Ferzandi, L. A. (2006). You can take it with you: Individual differences and expatriate effectiveness. Journal of Applied Psychology, 91, 109-125

Shapiro, J. M., Ozanne, J. L. \& Saatcioglu, B. (2008). An interpretive examination of the development of cultural sensitivity in international business. Journal of International Business Studies, 39(1), 71-87.

Sharma, R. R. (2019). Cultural Intelligence and Institutional Success: The Mediating Role of Relationship Quality. Journal of International Management, 25(3)

Shu, F., McAbee, S. T. \& Ayman, R. (2017). The HEXACO personality traits, cultural intelligence, and international student adjustment. Personality and Individual Differences, 106, 21-25.

Solomon, A. \& Steyn, R. (2017). Leadership styles: The role of cultural intelligence. SA Journal of Industrial Psychology, 43(1), 1-12. http://dx.doi.org/10.4102/sajip. v43i0.1436.

Spreitzer, G. M., McCall, M. W. \& Mahoney, J. D. (1997). Early identification of internationalexecutive potential. Journal of Applied Psychology, 82, 6 - 29. doi:10.1037/0021-9010.82.1.6

Sternberg, R. J. \& Detterman, D. K. (1986). What is intelligence? Contemporary viewpoints on its nature and definition. Norwood, NJ:Ablex.

Suharti, L., Handoko, Y. A. \& Huruta, A. D. (2019). Linking Cultural Intelligence and Adaptive Performance : Do Intercultural Interactions and Host University support Play Importand Roles? Business Management and Education, 17(1), 36-48.

Şahin, F. (2011). Liderin Kültürel Zekâsının Astların Örgütsel Vatandaşlık Davranışı ile İş Doyumu Üzerine Etkisi. Savunma Bilimleri Dergisi, 10(2), 80104

Şahin, F. \& Gürbüz, S. (2012). Kültürel Zekâ ve ÖzYeterliliğin Görev Performansı ve Örgütsel
Vatandaşlık Davranışı Üzerinde Etkisi: Çokuluslu Örgüt Üzerinde Bir Uygulama. The Journal of Industrial Relations \& Human Resources, 14(2), 125140 .

Şahin, F., Gürbüz, S., Köksal, O. \& Ercan, Ü. (2013a). Measuring cultural intelligence in the Turkish context. International Journal of Selection and Assessment, 21(2), 135-144.

Şahin, F., Gürbüz, S. \& Köksal, O. (2013b). Cultural intelligence (CQ) in action: The effects of personality and international assignment on the development of CQ. International Journal of Intercultural Relations, $59,152-163$

Şahin, F. \& Gürbüz, S. (2014). Cultural intelligence as a predictor of individuals' adaptive performance: A study in a multicultural environment. International Area Studies Review, 17(4), 394-413.

Şahin, F. \& Gürbüz, S. (2017). Entrepreneurial orientation and international performance: The moderating role of cultural intelligence. Journal of Management \& Organization, 1-25.

Takeuchi , R., Tesluk , P., Yun, S. \& Lepak D. (2005). An integrative view of international experiences: an emprical examination. Academy of Management Journal, 48, 85-100.

Taşdemir, D. D., Çekmecelioğlu, H. G. \& Yıkılmaz, İ. (2019). Çok Kültürlü Ortamda Çalışanların Kültürel Zekâ Düzeylerinin Duygusal Emek Gösterimlerine Etkisi. OPUS - International Journal of Society Research, 12, 719-740.

Tekin, E. (2019). Sosyal Zekânın Akademik Performans Üzerindeki Etkisinde Kültürel Zekânın Düzenleyici Rolü. Uluslararasi Ekonomi ve Yenilik Dergisi, 5(2), 115-135.

Templer, K. J., Tay, C. \& Chandrasekar, N. A. (2006). Motivational cultural intelligence, realistic job preview, realistic living conditions preview, and cross-cultural adjustment. Group \& Organization Management, 31(1), 154-173.

Thomas, D. C., Stahl, G., Ravlin, E. C., Poelmans, S., Pekerti, A., Maznevski, M., Lazarova, M. B., Elron, E., Ekelund, B. Z., Cerdin, J. L., Brislin, R., Aycan, Z. \& Au, K. (2008).Cultural intelligence: Domain and assessment. International Journal of Cross-Cultural Management, 8(2), 123-143.

Thomas, D. C. \& Inkson, K. (2005). Cultural Intelligence: people skills for a global workplace. Consulting to Management, 16(1).

Thomas, D. C., Liao, Y., Aycan, Z., Cerdin, J. L., Pekerti, A. A.,Ravlin, E. C.,...Moeller, M. (2015). Cultural intelligence: Atheory-based, shortformmeasure. 
Journal of International Business Studies, 46(9), 1099-1118.

Ting-Toomey, S. (1999). Communicating Across Cultures. New York: The Guilford Press

Triandis, H. C. (1994). Theoretical and methodological approaches to the study of collectivism and individualism. In, U. Kim, H. C. Triandis, Ç. Kagitçibasi, S. C. Choi \& G. Yoon (Ed.). Individualism and collectivism: Theory, method, and applications (ss. 41-51). Thousand Oaks, CA: Sage Publications

Tsai, Y. H., Joe, S. W., Lin, C. P., Wu, P. H. \& Cheng, Y. H. (2017). Modeling knowledge sharing among hightech professionals in culturally diverse firms: Mediating mechanisms of social capital. Knowledge Management Research \& Practice, 15, 225-237.

Tuan, L. T. (2016). From cultural intelligence to supply chain performance. The International Journal of Logistics Management, 27(1), 95-121.

Tung, R, L. (1988). The New Expatriates. Cambridge, MA: Bathnger.

Van Dyne, L., Ang, S. \& Koh, C. (2007). Development and validation of the CQS: The cultural intelligence scale. In, S. Ang \& L. Van Dyne (Ed.), Handbook oncultural intelligence: Theory, measurement and applications (ss. 16-38). Armonk, NY: M.E. Sharpe.

Velez-Calle, A., Pablo Roman-Calderon, J. \& RobledoArdila, C. (2018). The cross-country measurement invariance of the Business Cultural Intelligence Quotient (BCIQ). International Journal of Cross Cultural Management, 18(1), 72-85.

Vlajcic, D., Caputo, A., Marzi, G. vd. (2019). Expatriates managers' cultural intelligence as promoter of knowledge transfer in multinational companies. Journal of Business Research, 94, 367-377.

Wang, L., Wang, K. T., Heppner, P. P. \& Chuang, C. C. (2017). Cross-national cultural competency among Taiwanese international students. Journal of Diversity in Higher Education, 10(3), 271-287.

Wang, M. (2016). Effects of expatriates' cultural intelligence on cross-cultural adjustment and job performance. Revista de Cercetare si Interventie Sociala, 55, 231-243.

Ward, C., Fischer, R., Lam, F. S. Z. \& Hall, L. (2009). The convergent, discriminant, and incremental validity of scores on a self-report measure of cultural intelligence. Educational and Psychological Measurement, 69(1), 85-105.

Ward, C., Wilson, J. \& Fischer, R. (2011). Assessing the predictive validity of cultural intelligence over time.
Personality and Individual Differences, 51(2), 138142.

Wu, P. C. \& Ang, S. H. (2011). The impact of expatriate supporting practices and cultural intelligence on cross-cultural adjustment and performance of expatriates in Singapore. The International Journal of Human Resource Management, 22(13), 2683-2702.

Xu, X. J. \& Chen, X. P. (2017). Unlocking expatriates' job creativity: The role of cultural learning, and metacognitive and motivational cultural intelligence. Management and Organization Review, 13(4), 767794.

Yeşil, S. (2009). Kültürel Farklılıkların Yönetimi ve Alternatif Bir Strateji:Kültürel Zeka. KMU İ̈BF Dergisi, 11(16).

Yeşil, S. (2010). 21. Yüzyılın Küresel Örgütleri İçin Kültürel Zeka. Journal of the Cukurova University Institute of Social Sciences, 19(2), 147-168.

Yıldırım Ulusoy, H. \& Köroğlu, Ö. (2019). Turist Rehberlerinin Kültürel Zekâ Düzeyi ve Özyeterlilik İnançlarının Hizmet Sunumuna Etkisi. Gaziantep University Journal of Social Sciences, 18(1), 328347.

Yunlu, D. G. \& Clapp-Smith, R. (2014). Metacognition, cultural psychological capital and motivational cultural intelligence. Cross Cultural Management, 21(4), 386-399.

Zhang,Y. \& Oczkowski, E. (2016). Exploring the potential effectsof expatriate adjustment direction. Cross Cultural \&Strategic Management, 23(1), 158183.

Zhou, C., Hu, N. Wu, J. \& Gu, J. (2018) A new scale to measure cross-organizational cultural intelligence: Initial development and validation. Chinese Management Studies, 12(3), 658-679. 